\title{
EL ACUERDO TRANSATLÁNTICO PARA EL COMERCIO Y LA INVERSIÓN (TTIP): ORÍGENES, MOTIVACIONES Y POTENCIALES IMPACTOS EN LAS RELACIONES ENTRE ESTADOS UNIDOS Y LA UNIÓN EUROPEA
}

\author{
Gustavo Vega Cánovas \\ Francisco Campos OrTiz
}

\section{INTRODUCCIÓN}

DURANTE LOS ÚlTimos DOSCIENTOS AÑos, la economía internacional ha sido dominada por los países del Atlántico Norte, en primer lugar por Europa Occidental, por sí sola, y posteriormente por Europa y Estados Unidos, con un claro liderazgo de este último a partir de la conclusión de la Segunda Guerra Mundial. Sin embargo, en los próximos años es previsible que se consolide la pérdida del peso relativo del eje del Atlántico septentrional en la economía internacional -que empezó a sentirse desde hace dos décadas y se aceleró con la Gran Recesión- en favor de los países emergentes, especialmente aquellos en Asia.

A la luz de este escenario, a lo cual hay que añadir que las economías transatlánticas se encuentran fuertemente endeudadas y aquejadas por un magro crecimiento económico, Estados Unidos y los países de la Unión Europea han iniciado negociaciones para conformar una Asociación Transatlántica para el Comercio y la Inversión (TTIP, por sus siglas en inglés), la cual constituiría el área de libre comercio más amplia y profunda en el orbe, con una cobertura de casi $50 \%$ del PIB mundial, $30 \%$ del comercio global de 
mercancías, $40 \%$ del de servicios y $20 \%$ de los flujos de inversión extranjera directa (IED). ${ }^{1}$

Las negociaciones del TTIP se proponen alcanzar un acuerdo de libre comercio "integral y de altos estándares", teniendo como objetivo incrementar el acceso a los mercados transatlánticos mediante la disminución de barreras al comercio y la inversión, así como la armonización de medidas regulatorias. ${ }^{2}$ La reducción de aranceles no se considera un tema crítico de la negociación, pues se reconoce que se encuentran a niveles sustancialmente bajos. Antes bien, son las diferencias en los entramados regulatorios en ambos lados del Atlántico -que afectan especialmente el comercio de alto valor agregado- las que se considera imponen obstáculos muy significativos al comercio.

Lo anterior se añade a la complejidad del proceso, dado que la dificultad en la negociación de medidas regulatorias excede aquella de medidas arancelarias. Al discutir la aplicación de aranceles se cuenta con mecanismos que permiten cuantificar su impacto con precisión, facilitando la negociación de compensaciones. En el caso de las medidas regulatorias, resulta más complicado identificar con exactitud su impacto potencial, lo que dificulta cualquier negociación compensatoria entre las partes involucradas.

Si bien las autoridades de Estados Unidos y la Unión Europea han enfatizado los enormes beneficios económicos que el TTIP generaría de ser negociado exitosamente, partimos del supuesto de

${ }^{1}$ Misión de la Unión Europea en los Estados Unidos, "Transatlantic Trade and Investment Partnership (TTIP): Creating Jobs, Boosting Exports, and Investing in the Economy of Tomorrow", hoja de datos, agosto de 2013, http://www. euintheus.org/wp-content/uploads/2013/07/TTIP_Publicatiopn_85x11in_ High_res.pdf (04/02/2016); oEcD, "The Transatlantic Trade and Investment Partnership: Why Does It Matter?”, febrero de 2013, p. 1, http:/ /www.oecd.org/trade/ TTIP.pdf (04/02/2016).

${ }^{2}$ De acuerdo al artículo xxiv del Acuerdo General sobre Aranceles Aduaneros y Comercio (GATT), un acuerdo de libre comercio de "altos estándares" cubre sustancialmente todo el comercio entre las partes, eliminando las regulaciones restrictivas al comercio. Si el acuerdo también cubre el sector de servicios, el Acuerdo General sobre el Comercio de Servicios (GATs) describe un acuerdo de "altos estándares" como aquel en el que está ausente cualquier forma de discriminación en el trato nacional de todos los sectores cubiertos. 
que el acuerdo no está exento de un propósito geopolítico subyacente. Por un lado, busca revitalizar la relación transatlántica para afrontar la tendencia de que en el futuro cercano el crecimiento económico más dinámico se consolide en la cuenca del Pacífico, nutriendo el potencial de que sean las economías asiáticas las que impongan su predominio; por otro lado, busca recuperar para Estados Unidos y la Unión Europea el poder para establecer las reglas básicas de la economía internacional del que gozaron después de la Segunda Guerra Mundial.

Estas aspiraciones no serán fáciles de alcanzar. En primer lugar será necesario que Estados Unidos y la Unión Europea acuerden las nuevas reglas de comercio, lo que resultará muy complejo a la luz de las diferentes tradiciones regulatorias en cada lado del Atlántico. En segundo lugar, aunque las negociaciones resultaran exitosas, no existe certeza de que los países emergentes se ajusten a las nuevas reglas pactadas. De no ser así, la economía internacional podría fragmentarse en procesos de integración regional antagónicos, lo que implicaría un severo golpe para la ya de por sí debilitada Organización Mundial de Comercio (OMC).

El presente artículo tiene como objetivo realizar un estudio y evaluación sobre los orígenes, las motivaciones principales, los prospectos y las consecuencias previsibles de la potencial entrada en vigor del TTIP, así como los principales obstáculos que está enfrentando y que encarará a futuro la negociación del acuerdo.

La primera sección presenta una evaluación de la relación comercial y de inversiones entre Estados Unidos y la Unión Europea, a fin de comprender mejor las implicaciones de la negociación de un acuerdo comercial mega-regional. En la segunda sección se discuten las justificaciones que tanto Estados Unidos como la Unión Europea han ofrecido para negociar el TTIP, y se destacan las principales motivaciones que las partes interesadas tienen para completarlo. En la tercera sección se analiza el proceso de evolución que ha seguido la negociación del TTIP desde su concepción, así como las dificultades que ha enfrentado y enfrentará en el futuro. En esta sección también se destacan los potenciales efectos económicos que se estima produzca el acuerdo. La 
última sección ofrece una serie de conclusiones y reflexiones sobre los prospectos del TTIP.

\section{LAS RELACIONES COMERCIALES Y DE INVERSIÓN ENTRE Estados Unidos Y LA UNión EUROPEA}

Estados Unidos y la Unión Europea tienen un papel esencial en el sistema de comercio mundial. Estados Unidos aporta $8.3 \%$ del total de exportaciones de bienes en el mundo y $12.3 \%$ de las importaciones. De manera similar, su participación en las exportaciones mundiales de servicios es de $13.9 \%$ del total, mientras que importa $9.4 \%$ del total. Por su parte, las exportaciones de bienes de la Unión Europea al mundo equivalen a 15.3\% del total, mientras que sus importaciones son de $14.7 \%$ del total mundial. En lo que corresponde al comercio de servicios, la Unión Europea aporta $25.1 \%$ de las exportaciones mundiales y $19.7 \%$ de las importaciones (tabla 1$).^{3}$

En términos de exportaciones, los principales socios comerciales de la Unión Europea son, por orden de importancia, Estados Unidos (18.3\% del total), China (9.7\%), Suiza (8.2\%), Rusia $(6.1 \%)$ y Turquía $(4.4 \%)$. En cuanto a las importaciones, sus principales socios son China (17.9\% del total), Estados Unidos (12.2\%), Rusia $(10.8 \%)$, Suiza $(5.7 \%)$ y Noruega $(5.2 \%) .{ }^{4}$

Los principales destinos de las exportaciones de Estados Unidos son, por orden de magnitud, Canadá (19.2\% del total), la Unión Europea (17\%), México (14.8\%), China (7.6\%) y Japón $(4.1 \%)$. De manera similar, los principales puntos originarios de sus importaciones son China (19.9\% del total), la Unión Europea (17.8\%), Canadá $(14.8 \%)$, México $(12.5 \%)$ y Japón $(5.7 \%) .{ }^{5}$

${ }^{3}$ Todas las cifras en este párrafo han sido extraídas de: omc, Base de Datos Estadísticos. Perfiles Comerciales, septiembre de 2014, http://stat.wto.org/CountryProfile/WSDBCountryPFReporter.aspx?Language=S (04/02/2016).

${ }^{4}$ Oficina Europea de Estadística (Eurostat), "Extra-EU Trade by Partner", noviembre de 2015, http://appsso.eurostat.ec.europa.eu/nui/submitViewTableAction.do $(03 / 12 / 2015)$

${ }^{5}$ Oficina de Censos de los Estados Unidos, "Foreign Trade: Trade with Euro- 
Así, encontramos que Estados Unidos y la Unión Europea son mutuamente relevantes. Para el primero, la Unión Europea es el segundo principal destino de sus exportaciones y el segundo origen del que más importa bienes. En paralelo, Estados Unidos es el principal destino de las exportaciones de la Unión Europea y el tercer país del que más importa bienes.

\section{TABLA 1}

Participación de la Unión Europea y Estados Unidos en el Comercio Mundial

Comercio de bienes en el mundo

\begin{tabular}{lrcl}
\hline & EE. UU. & UE & Conjunto \\
\hline \% Exportaciones & $8.39 \%$ & $15.33 \%$ & $23.72 \%$ \\
\% Importaciones & $12.33 \%$ & $14.78 \%$ & $27.11 \%$ \\
\hline \multicolumn{5}{c}{ Comercio de servicios en el mundo } \\
\hline \multicolumn{5}{c}{ EE. UU. } & UE & Conjunto \\
\hline \% Exportaciones & $13.92 \%$ & $25.19 \%$ & $39.11 \%$ \\
\% Importaciones & $9.44 \%$ & $19.74 \%$ & $29.18 \%$ \\
\hline
\end{tabular}

Fuente: omc, Base de Datos Estadísticos, "Perfiles Comerciales", septiembre de 2014. Disponible en http://stat.wto.org/CountryProfile/WSDBCountryPFReporter.aspx? Language $=$ S $(04 / 02 / 2016)$.

En 2014, la relación comercial bilateral entre Estados Unidos y la Unión Europea alcanzó un monto total de 1090000 millones de dólares, con un balance negativo para Estados Unidos por 93000 millones de dólares (gráfica 1). Del total, 702000 millones de dólares del comercio bilateral $(64 \%)$ correspondieron al comercio de bienes y 388000 millones de dólares (36\%) al de servicios. ${ }^{6}$

pean Union", septiembre 2015, disponible en http://www.census.gov/foreign-tra de/balance/c0003.html (03/12/2015).

${ }^{6}$ Todas las cifras en este párrafo han sido extraídas de: Oficina de Análisis Económico de los Estados Unidos, "U.S. Trade in Goods and Services by Selected Countries and Areas, 1999 - present", diciembre de 2015, http://www.bea.gov/ international/index.htm\#trade (04/02/2015). 


\section{GRÁFICA 1}

Comercio de Estados Unidos con la Unión Europea, 1999-2014 (miles de millones de dólares)

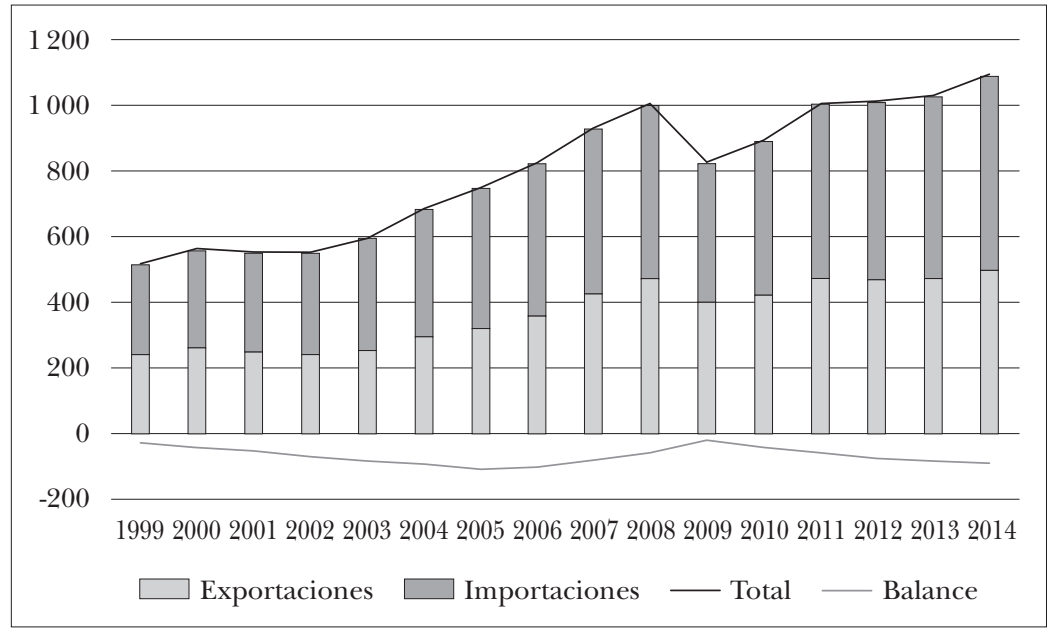

Fuente: Elaboración propia con datos de la Oficina de Análisis Económico de EE.UU. (вEA), junio de 2015.

La estructura del comercio entre ambas partes en lo que corresponde a bienes y servicios se ha mantenido relativamente estable durante los pasados quince años (gráfica 2). En 1999, el comercio de bienes representó casi $70 \%$ de la relación comercial bilateral, al tiempo que en 2014 esta proporción fue de $64 \%$, una disminución de 9 o $0.6 \%$ anual. ${ }^{7}$ Así, el intercambio de bienes continúa siendo prevalente en la relación comercial bilateral.

Pese a que aún representa una proporción significativamente menor que el comercio de bienes, el comercio de servicios tuvo mayor crecimiento en los quince años pasados. Mientras que el comercio de bienes ha crecido $201 \%$, a una tasa de crecimiento anual compuesta (CAGR) de $4.8 \%$, aquel de servicios ha aumentado $237 \%$, a una CAGR de $5.9 \%$. El comercio total ha aumentado $213 \%$, a una CAGR de $5.2 \%$. Es decir, el comercio de servicios entre

\section{${ }^{7}$ Loc. cit.}


GrÁFICA 2

Comercio de bienes y servicios entre la Unión Europea y Estados Unidos (\% del total)

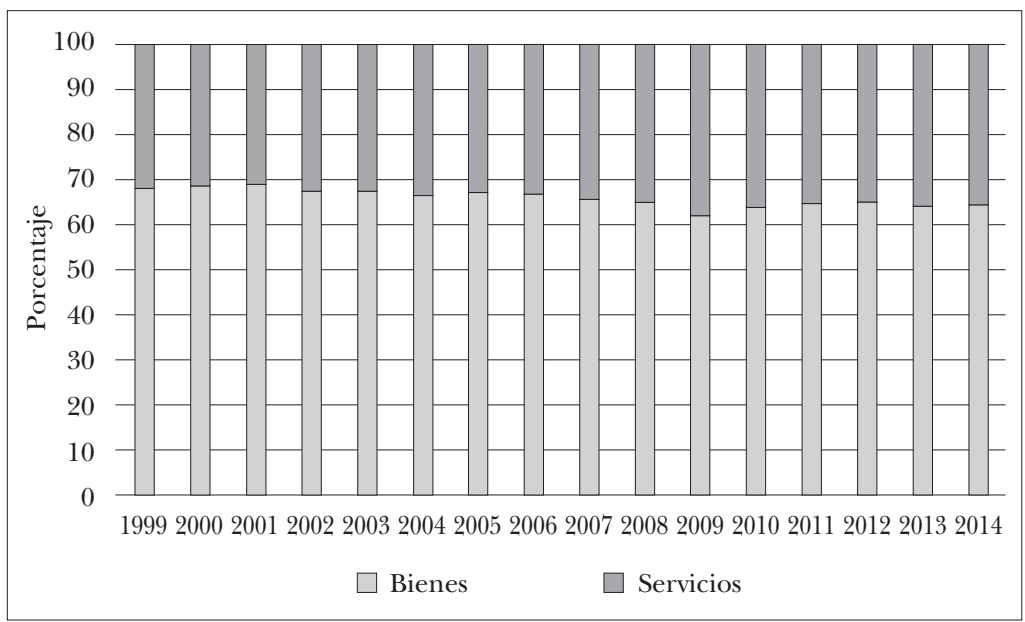

Fuente: Elaboración propia con datos de la Oficina de Análisis Económico de EE. UU. (BEA), junio de 2015.

Estados Unidos y la Unión Europea incluso ha crecido a mayor ritmo que el comercio total en los quince años pasados. ${ }^{8}$

En el comercio de bienes, las importaciones de Estados Unidos desde la Unión Europea han crecido a mayor velocidad (215\%) que las exportaciones hacia la Unión Europea (183\%). En el sector de servicios se observa un fenómeno inverso, ya que el crecimiento de las exportaciones desde Estados Unidos hacia la Unión Europea (243\%) supera las importaciones del primero desde el segundo (229\%), aunque por un margen relativamente pequeño (gráfica 4$) .9$

${ }^{8}$ Cálculos propios a partir de datos de: Oficina de Análisis Económico de los Estados Unidos, "U.S. Trade in Goods and Services by Selected Countries and Areas, 1999 - Present”.

${ }^{9}$ Loc. cit. 
GRÁfica 3

Crecimiento del comercio de bienes y servicios de Estados Unidos con la Unión Europea

$($ Año base $=1999)$

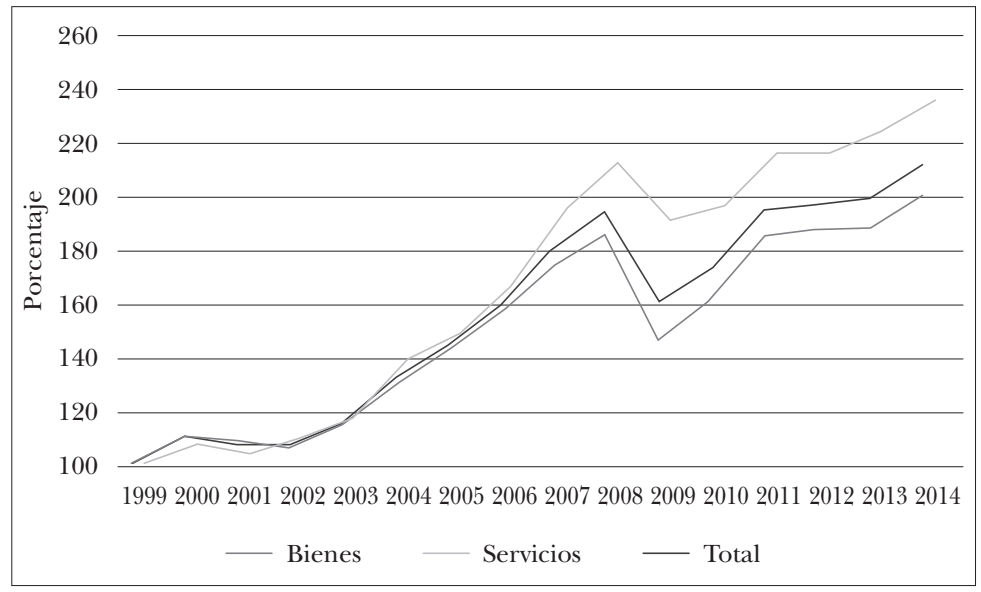

Fuente: Elaboración propia con datos de la Oficina de Análisis Económico de EE. UU. (BEA), junio 2015.

\section{GRÁFICA 4}

Comparación del crecimiento del comercio de bienes y servicios entre Estados Unidos y la Unión Europea (Año base = 1999)

\section{A. Crecimiento en el comercio de bienes}

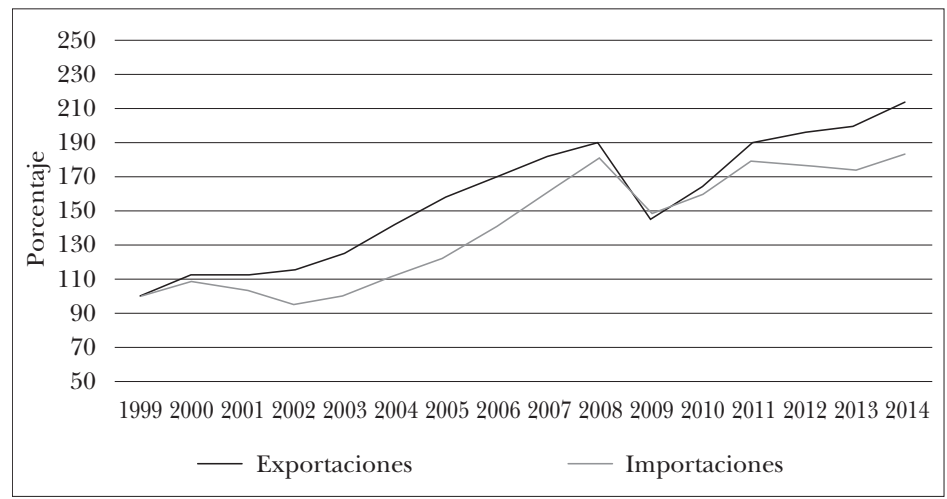


B. Crecimiento en el comercio de servicios

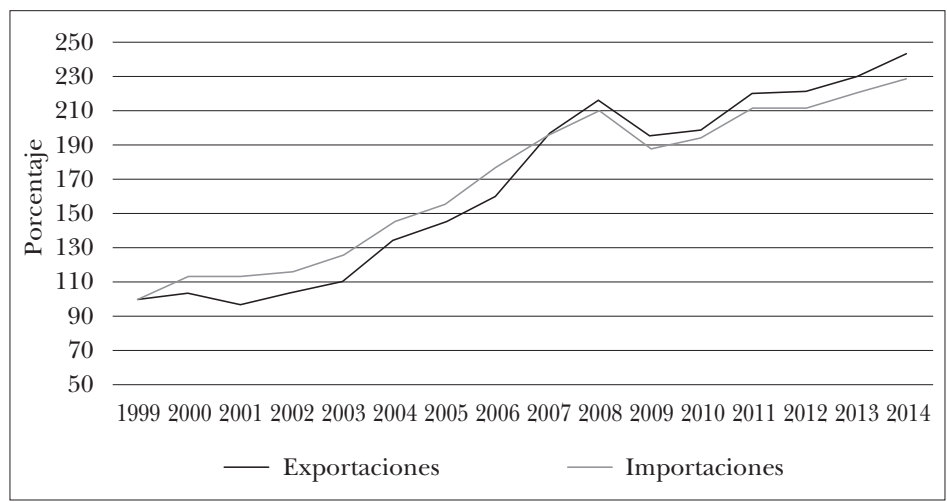

Fuente: Oficina de Análisis Económico de EE. UU. (BEA), Departamento de Comercio, junio de 2015.

En términos de bienes, la mayor parte del comercio bilateral se concentra en productos químicos, equipo de transporte, maquinaria no eléctrica, productos electrónicos y de cómputo, productos misceláneos manufacturados, manufacturas de metales primarios y productos derivados del petróleo y del carbón (tabla 2). ${ }^{10}$

En términos del comercio de servicios con el mundo, encontramos que para la Unión Europea los sectores preeminentes por su magnitud son aquellos de servicios de negocios, viajes, transportes, servicios financieros, derechos, licencias y cesión de derechos, y computación e informática. De manera similar, los principales sectores de exportación de servicios de Estados Unidos al mundo son los de viajes, servicios de negocios, transporte, derechos, licencias y cesión de derechos, y servicios financieros (tabla 3$) \cdot{ }^{11}$

10 Conferencia de las Naciones Unidas sobre Comercio y Desarrollo (UNCTAD), "Estadísticas sobre comercio internacional", junio de 2015.

${ }^{11}$ Loc. cit. 
Tabla 2

Exportaciones e importaciones de bienes de Estados Unidos hacia y desde la Unión Europea por principales tipos de productos

\section{A. Exportaciones}

Exportaciones de Estados Unidos a la Unión Europea

\begin{tabular}{lcc}
\hline \multicolumn{1}{c}{ Categoría } & $\begin{array}{c}\text { Miles de millones } \\
\text { de dólares }\end{array}$ & $\begin{array}{c}\text { \% del } \\
\text { total }\end{array}$ \\
\hline Productos químicos & 54.8 & 20 \\
Equipo de transporte & 47.5 & 17 \\
Productos eléctricos y de cómputo & 32.7 & 12 \\
Maquinaria, excepto eléctrica & 22.8 & 8 \\
Productos misceláneos manufacturados & 22.4 & 8 \\
Productos derivados del petróleo y el carbón & 17.5 & 6 \\
Productos electrónicos, sus partes y componentes & 8.9 & 3 \\
Manufacturas de metales primarios & 8.7 & 3 \\
Fabricación de productos de metal & 6.8 & 2 \\
Mercancía usada o de segunda mano & 6.8 & 2 \\
Productos agrícolas & 6.7 & 2 \\
Minerales metálicos y otros & 5.5 & 2 \\
Alimentos manufacturados & 4.4 & 2 \\
Productos de plástico y caucho & 4.0 & 1 \\
Papel & 3.1 & 1 \\
Residuos y desechos & 2.9 & 1 \\
Otros & 20.3 & 10 \\
\hline
\end{tabular}

En lo que respecta a la inversión extranjera directa (IED) entre la Unión Europea y Estados Unidos, en 2012 los flujos bilaterales alcanzaron un monto de 271000 millones de dólares. Los flujos de IED desde Estados Unidos hacia la Unión Europea fueron de 166000 millones de dólares, lo que implicó un crecimiento de $183 \%$ con respecto a 2001, es decir, una CAGR de 10\%. Los flujos de IED desde la Unión Europea hacia Estados Unidos en 2012 sumaron 105000 
millones de dólares, marcando un crecimiento de $45 \%$ con respecto a 2001, es decir, una CAGR de 3\%. En general, para la mayor parte de los años entre 2001 y 2012 la IED de Estados Unidos en la Unión Europea fue mayor que la IED de origen europea en Estados Unidos (gráfica 5), además de que su tasa de crecimiento en el periodo fue significativamente mayor. ${ }^{12}$

\section{B. Importaciones}

Importaciones de Estados Unidos desde la Unión Europea

\begin{tabular}{lcc}
\hline \multicolumn{1}{c}{ Categoría } & Miles de millones de dólares & \% del Total \\
\hline Productos químicos & 90.4 & 22 \\
Equipo de transporte & 83.5 & 20 \\
Maquinaria excepto eléctrica & 52.6 & 13 \\
Productos eléctricos y de cómputo & 28.5 & 7 \\
Productos derivados del petróleo y el carbón & 20.3 & 5 \\
Productos misceláneos manufacturados & 19.7 & 5 \\
Manufacturas de metales primarios & 14.6 & 3 \\
Fabricación de productos de metal & 14.5 & 3 \\
Productos electrónicos, sus partes & & \\
$\quad$ y componentes & 12.7 & 3 \\
Bebidas y productos derivados del tabaco & 11.8 & 3 \\
Alimentos manufacturados & 8.6 & 2 \\
Mercancía usada o de segunda mano & 8.1 & 2 \\
Productos de plástico y caucho & 6.6 & 2 \\
Minerales no metálicos & 4.6 & 1 \\
Productos a base de cuero y afines & 4.1 & 1 \\
Papel & 3.1 & 1 \\
Otros & 33.4 & 7 \\
\hline
\end{tabular}

Fuente: Conferencia de las Naciones Unidas sobre Comercio y Desarrollo (UNCTAD), "Estadísticas sobre Comercio Internacional”, junio de 2015.

12 Cálculos propios a partir de datos de: Oficina de Análisis Económico de los Estados Unidos, "U.S. Direct Investment: Balance of Payments and Direct Investment Position Data", junio de 2015, http://www.bea.gov/international/dilusdbal.htm (04/02/2016). Todos los datos sobre IED mencionadas en esta sección han sido extraídos de esta misma fuente; los cálculos son propios. 
TABLA 3

Comercio de servicios de la Unión Europea y Estados Unidos con el resto del mundo, 2004-2014

\begin{tabular}{lcccccc}
\hline Sector & \multicolumn{3}{c}{$\begin{array}{c}\text { UE } \\
\text { Crecimiento }\end{array}$} & $\begin{array}{c}\text { \% del } \\
\text { total }\end{array}$ & \multicolumn{3}{c}{$\begin{array}{c}\text { EE. UU. } \\
\text { Crecimiento }\end{array}$} & \% del \\
& CAGR & Total & total \\
\hline Total & 6 & 76 & 100 & 7 & 82 & 100 \\
Transporte & 6 & 76 & 21 & 7 & 82 & 17 \\
Viajes & 5 & 60 & 23 & 5 & 52 & 24 \\
Comunicaciones & 3 & 33 & 3 & 5 & 58 & 2 \\
Construcción & 9 & 124 & 2 & 10 & 130 & 1 \\
Seguros & 6 & 63 & 3 & 6 & 62 & 7 \\
Servicios financieros & 5 & 52 & 6 & 7 & 80 & 9 \\
Computación e informática & 8 & 99 & 5 & 9 & 116 & 3 \\
Derechos, licencias y cesión & & & & & & \\
de derechos & 12 & 169 & 6 & 11 & 157 & 15 \\
Otros servicios de negocios & 10 & 138 & 28 & 7 & 84 & 18 \\
Servicios, personales, & & & & & & \\
culturales y recreativos & 8 & 98 & 1 & 11 & 146 & 0 \\
Servicios gubernamentales & 5 & 60 & 1 & 19 & 369 & 5 \\
\hline
\end{tabular}

Fuente: Elaboración propia a partir de datos de: Conferencia de las Naciones Unidas sobre Comercio y Desarrollo (UNCTAD), "Estadísticas sobre Comercio Internacional”, junio de 2015.

Cabe destacar que Estados Unidos es la principal fuente de IED en la Unión Europea. Del total de IED recibida por la Unión Europea en 2012, aquella proveniente de Estados Unidos representó 39\% del total. La mayor parte de dicha inversión se concentró en el sector de servicios financieros, seguido del manufacturero, del que los rubros con mayor concentración de inversión estadounidense son el petroquímico y farmacéutico.

La Unión Europea es también la principal fuente de los flujos de IED que arriban a Estados Unidos, si bien en este caso la concentración es mayor. Del total de la IED recibida por Estados Unidos en 2013, aquella proveniente de países de la Unión 
Europea implicó $67 \%$ del total. La región de origen de IED que le sigue en magnitud, Asia Pacífico, aporta tan sólo 19\% del total. De esta forma queda evidenciada la primacía e importancia económica de los flujos de IED desde la Unión Europea hacia Estados Unidos.

\section{GRÁFICA 5}

Flujos de IED de Estados Unidos con la Unión Europea (miles de millones de dólares)

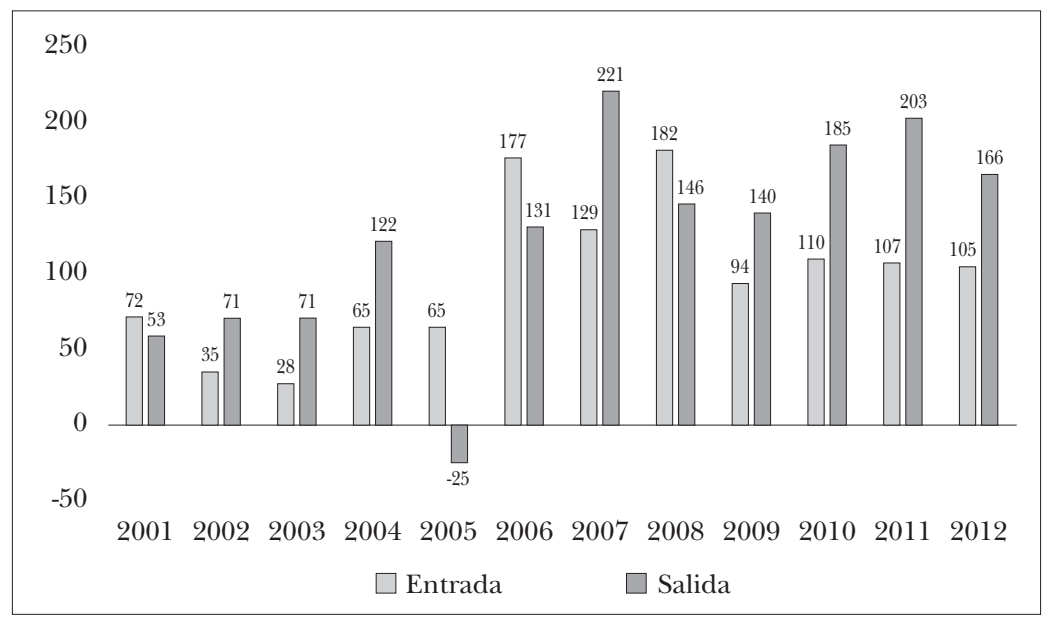

Fuente: Elaboración propia con datos de la Oficina de Análisis Económico de EE. UU. (BEA), junio de 2015.

Entre 2001 y 2012, los principales países de la Unión Europea que invirtieron en Estados Unidos fueron Reino Unido (27\% del total), Países Bajos (20\%), Alemania (14\%), Francia (13\%) y Bélgica $(10 \%)$ (gráfica 6.A). De manera similar, los países de la Unión Europea que recibieron mayor IED proveniente de Estados Unidos en el mismo periodo son Países Bajos (31\%), Reino Unido (23\%), Luxemburgo (17\%), Irlanda (12\%) y Alemania (5\%) (gráfica 6.B). 


\section{GrÁFica 6}

IED acumulada de los países de la Unión Europea en Estados Unidos y de Estados Unidos en países de la Unión Europea (2001-2012)

A. IED de la Unión Europea acumulada en Estados Unidos por países de origen

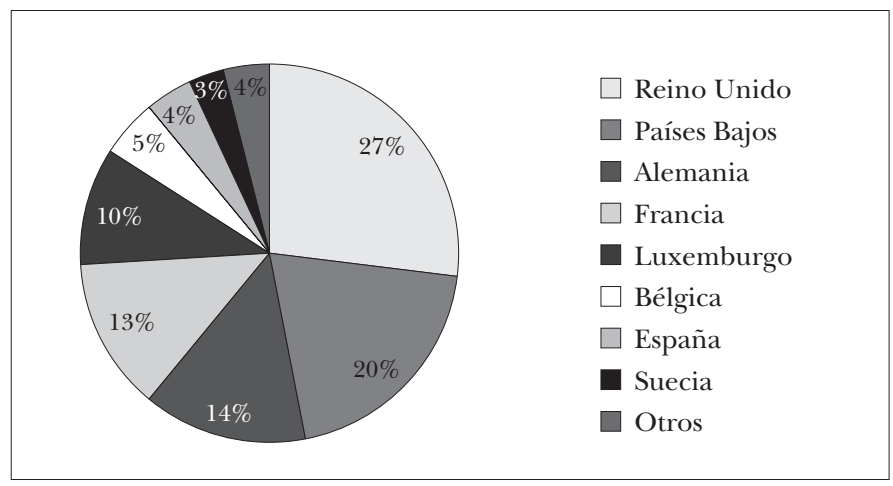

B. IED originaria de Estados Unidos acumulada en la Unión Europea por país receptor

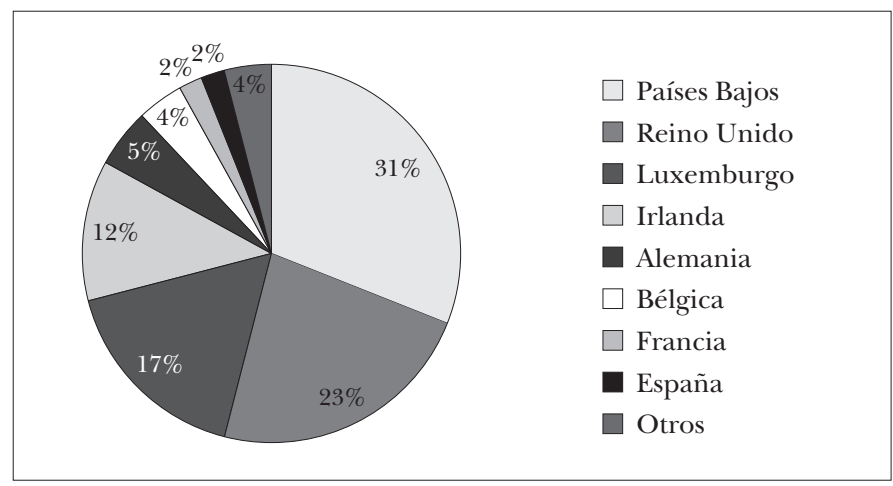

Fuente: Oficina de Análisis Económico de EE. UU. (BEA), junio de 2015. 
En resumen, es un hecho que pese al enorme dinamismo y crecimiento que han alcanzado las economías asiáticas y emergentes en los últimos años, Estados Unidos y la Unión Europea aún son dos jugadores relevantes en la economía internacional, al tiempo que mantienen una relación económica bilateral abierta, fluida, vigorosa, con gran potencial de expansión y con una importancia trascendental para la economía mundial.

\section{MotiVACIONES Y OBJETIVOS PRINCIPALES DEL TTIP PARA Estados Unidos Y LA UNIÓN EUROPEA}

Como se dijo, las autoridades de Estados Unidos y de la Unión Europea han promovido el TTIP en razón de los beneficios económicos que les atraería. Un estudio encargado por la Comisión Europea en 2013 concluyó que un acuerdo amplio entre ambas partes podría rendir 119000 millones de euros para la Unión Europea y 95000 millones de euros para Estados Unidos. Estas ganancias serían alcanzadas por un aumento de los volúmenes comerciales de 6\% anual en la Unión Europea y 8\% en Estados Unidos. Dado que los niveles arancelarios son bajos entre ambas regiones, $80 \%$ del crecimiento se generaría por la reducción de barreras no arancelarias, especialmente por la liberación del comercio de servicios y de compras gubernamentales, ${ }^{13}$ así como por la simplificación de los procesos administrativos aduanales y la homogeneización de las medidas regulatorias. Adicionalmente, el reporte vaticina que el impacto de un TTIP amplio y ambicioso tendría un impacto positivo para el resto del mundo equivalente a 100000 millones de euros por concepto de creación de comercio, mientras que un gran número de empleos se crearía en diversos sectores. ${ }^{14}$ Cabe mencionar

${ }^{13}$ Las negociaciones en relación a compras gubernamentales aún no han comenzado y se estima que lo harán en febrero de 2016. Hasta ahora sólo se han llevado a cabo reuniones técnicas preliminares. Se ha acordado que la base de la negociación sea el Acuerdo sobre Contratación Pública de la omc. Véase: Comisión Europea, Reporte de la Décimo Primer Ronda de Negociaciones del TTIP, Miami, octubre de 2015, p. 3.

${ }^{14}$ Véase Joseph Francois, "Reducing Transatlantic Barriers to Trade and In- 
que esos resultados son consistentes con estimados llevados a cabo en Estados Unidos. ${ }^{15}$

En suma, en un entorno de bajo crecimiento económico en la región transatlántica y de limitadas posibilidades de incrementos en las inversiones públicas para generarlo, la liberación comercial se plantea como una solución que, aunque no parece suficiente para subsanar los impactos negativos de la Gran Recesión ni para superar los problemas de la unión monetaria europea, sí podría promover ganancias en ingreso y bienestar a un costo cero para las finanzas públicas de ambas partes. Este beneficio por sí solo convierte al TTIP en una iniciativa encomiable.

Es un hecho que los beneficios potenciales de un acuerdo de este tipo se reconocieron por lo menos desde hace un par de décadas en ambos lados del Atlántico; sin embargo, es hasta 2013 que se tomó la decisión de iniciar una negociación para convertirlos en realidad. ${ }^{16}$ La pregunta que surge, entonces, es por qué hasta la segunda década del siglo xxi se dio comienzo a las negociaciones. La respuesta, en nuestra opinión, está relacionada con los cambios globales que se han expresado en los últimos dos decenios, mismos que se avivaron a raíz de la Gran Recesión.

\section{El TTIP como respuesta a los cambios en el poder económico a nivel mundial}

Desde la década de 1980, cuando se aceleró el proceso de globalización de la economía internacional, el punto focal del dinamismo económico a nivel mundial se ha desplazado lentamente del

vestment: An Economic Assessment", Londres, Centre for Economic Policy Research, marzo de 2013.

${ }^{15}$ Véase Shayerah Ilias Akhtar y Vivian C. Jones, "Transatlantic Trade and Investment Partnership (TTIP) Negotiations", Congressional Research Service, febrero de 2014, R43387.

${ }^{16}$ Ya desde 1995 el entonces ministro de Comercio de la Unión Europea, sir Leon Brittan, el primer ministro del Reino Unido, John Major, y el ministro de Exteriores alemán, Klaus Kinkel, promovieron la creación de una zona de libre comercio del Atlántico Norte. La propuesta no prosperó en aquel momento. 
Atlántico al Pacífico. En un principio estos cambios no impusieron un desafío al liderazgo -económico, político y cultural- de las economías atlánticas. Las economías emergentes simplemente tuvieron que adoptar las reglas impuestas por los países de Occidente. Sin embargo, con la explosión de la crisis financiera internacional de 2008, y la Gran Recesión que incitó, el proceso de convergencia entre las principales economías emergentes -especialmente de Asia- y las economías avanzadas de Occidente se ha acelerado. Mientras que las primeras resultaron poco afectadas por la crisis, y de hecho la superaron rápidamente, las segundas se han visto permeadas por círculos viciosos de bajo crecimiento económico y alto endeudamiento que les ha impedido -especialmente en la eurozona- recuperar el liderazgo que tuvieron en el pasado.

La creciente importancia de los países en desarrollo en el campo económico mundial es innegable desde toda perspectiva. De acuerdo con el Fondo Monetario Internacional (FMI), la participación de los países emergentes y en desarrollo en la economía mundial ha pasado de $42.6 \%$ en 2000 a $57 \%$ en 2015; la misma institución prevé que para 2020 tal participación será de 60\% (gráfica 6). De manera relacionada, la participación de Estados Unidos y la Unión Europea en la economía mundial se ha ido deteriorando y se prevé que continuará haciéndolo a futuro.

Teniendo en cuenta lo anterior, así como el hecho de que en los últimos años se han expresado claros cuestionamientos a los modelos económicos de Estados Unidos y la Unión Europea -y a su liderazgo-, consideramos que el TTIP puede percibirse como una reacción de Estados Unidos y la Unión Europea a su declive relativo, y como un instrumento para recuperar su prominencia en los asuntos económicos internacionales.

El propósito de Estados Unidos y la Unión Europea es revitalizar su poder en forma indirecta -es decir, sin provocar un conflicto con las economías emergentes-mediante la creación de nuevas reglas en la esfera económica internacional. De manera similar a como lo hicieron al crear el GATT, la meta es redefinir la estructura económica internacional con base en lineamientos que reflejen sus valores, preferencias e intereses. 


\section{GrÁFICA 6}

Participación porcentual de países y grupos de países en el PIB PPP mundial
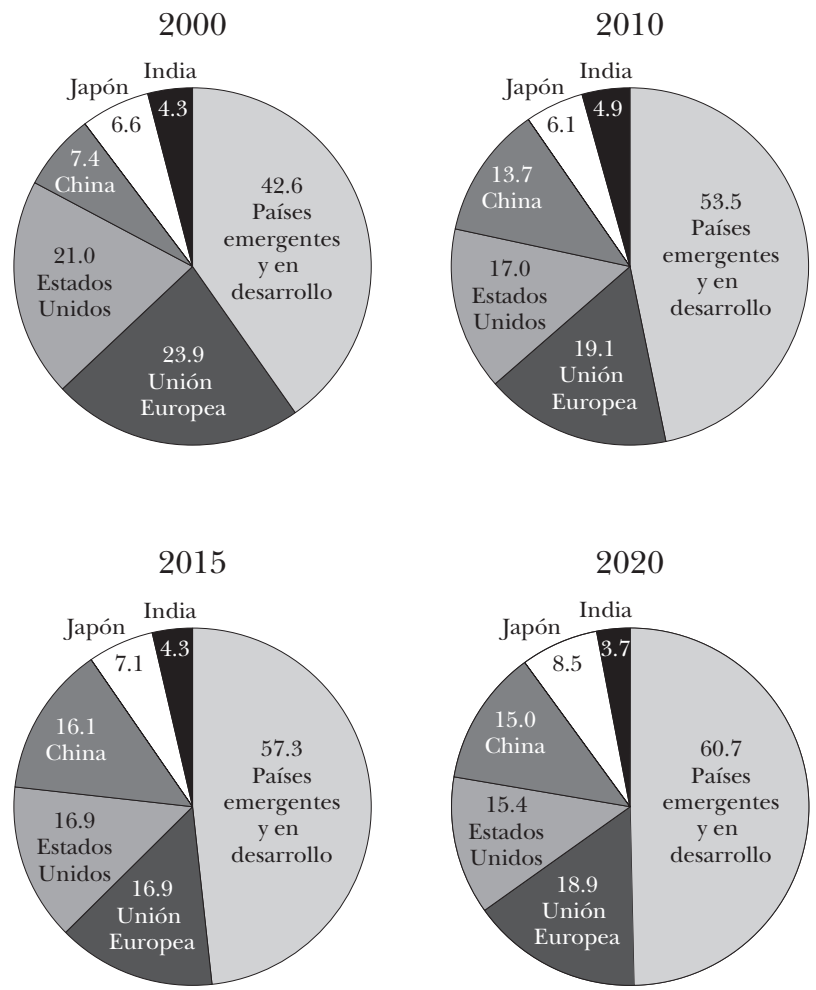

Fuente: FMI, IMF Data Mapper: World Economic Outlook, abril 2015. Disponible en http://www.imf.org/external/datamapper/index.php

La cuestión es que es imposible implementar esta redefinición como en el pasado, a través de organizaciones multilaterales como la омc, cuya ronda de negociaciones denominada Doha se encuentra paralizada precisamente porque las economías emergentes no han estado dispuestas a aceptar los dictados de Estados Unidos y la Unión Europea. En virtud de lo anterior, Estados Unidos y la Unión Europea se han propuesto forjar nuevas regulaciones en aras de 
consolidar un mercado transatlántico que, al tiempo que promueva un nuevo crecimiento para sus economías, atraiga también el interés comercial de países en desarrollo cuyo éxito todavía depende en buena medida de afianzar sus ventas en las economías desarrolladas.

En el escenario de que el TTIP se concrete, el mensaje para las economías emergentes será muy claro: si quieren preservar el acceso de sus productos a los mercados transatlánticos, tendrán que aceptar las nuevas reglas aplicables en la mega-región gradualmente, pues de otra manera su acceso quedará restringido, lo que se reflejará negativamente en su crecimiento económico.

En el caso de Estados Unidos, esta estrategia se implementa en paralelo al anunciado giro de su política exterior hacia la región de Asia Pacífico, del que el Acuerdo de Asociación Transpacífico (TPP, por sus siglas en inglés) es el bastión. Si bien con intereses diferenciados tanto en Asia Pacífico como en el marco transatlántico, Estados Unidos se propone liderar una reingeniería del sistema comercial internacional. El propósito estadounidense es avanzar su proyecto económico de liberalización mediante la evasión de la parálisis que aqueja las negociaciones multilaterales en el seno de la omc. ${ }^{17}$

Pero, ¿qué características tienen estas nuevas reglas propuestas para el marco comercial transatlántico? ¿Cómo surgen, qué evolución han tenido y para qué sectores se están contemplando? ¿Cuáles son los principales temas, objetivos y problemáticas en la negociación del TTIP? En las siguientes dos secciones nos ocupamos de responder estas cuestiones.

\section{NATURALEZA, ORÍGENES Y AVANCES DE LAS NEGOCIAGIONES DEL TTIP}

Como se ha dicho, el TTIP es un acuerdo de libre comercio "integral y de altos estándares” que actualmente negocian Estados Unidos y

${ }^{17}$ En este sentido, se habla de que "el interregionalismo reemplazaría al multilateralismo como modo de acercamiento entre las dos principales potencias del mundo". Véase Stephan Joseph Sberro Picard, "La negociación del TTIP: del interregionalismo a la gobernanza global”, CIDOB d'Afers Internacionals, núm. 110, septiembre de 2015, p. 78. 
la Unión Europea. El objetivo en las negociaciones es robustecer los mercados transatlánticos mediante la disminución de barreras al comercio y la inversión, así como la armonización de medidas regulatorias. ${ }^{18}$ Ambas partes también aspiran a utilizar los estándares negociados en el TTIP como base para futuras negociaciones comerciales, avanzando en la liberalización comercial y estableciendo criterios mínimos que en el futuro sirvan como modelo para el sistema de comercio multilateral.

Tras la Cumbre Unión Europea-Estados Unidos de noviembre de 2011, los líderes de ambas entidades instruyeron al Consejo Económico Transatlántico crear un Grupo de Alto Nivel sobre Empleo y Crecimiento Económico. El objetivo de este grupo, liderado por el representante comercial de Estados Unidos y el comisionado de Comercio de la Unión Europea, fue identificar políticas para incrementar el comercio y la inversión entre Estados Unidos y la Unión Europea, promoviendo la creación de empleo, el crecimiento económico y la competitividad.

En febrero de 2013, el grupo de trabajo presentó su reporte final, en el que destacó que los intercambios de comercio e inversión entre la Unión Europea y Estados Unidos conforman la columna vertebral de la economía mundial. En conjunto, la Unión Europea y Estados Unidos suman casi la mitad del PIB mundial y un tercio del comercio global. Cada día, ambos socios comercian un total de 2700 millones de dólares, mientras que los intercambios de inversión transatlántica acumulan 4.1 billones de dólares. Las empresas estadounidenses tienen inversiones por 2.4 billones de dólares en la Unión Europea, mientras que las empresas europeas han invertido 1.7 billones de dólares en Estados Unidos. ${ }^{19}$

${ }^{18}$ Las negociaciones relacionadas al ámbito regulatorio cubren nueve sectores: farmacéutico, material médico, cosmético, textil, automotor, tecnología de la información y la comunicación, ingeniería, químicos y pesticidas.

19 Oficina del Presidente de los Estados Unidos, The Economic Benefits of U.S. Trade, mayo de 2015, p. 46, https://www.whitehouse.gov/sites/default/files/ docs/cea_trade_report_final_non-embargoed_v2.pdf (04/02/2016). [En el original en inglés: trillion; seguimos la forma hispánica billón: un millón de millones $\left(10^{12}\right)$. Ed.] 
La principal recomendación del grupo de trabajo fue la creación de un acuerdo amplio de comercio e inversión. Este acuerdo debía incluir, acorde a las recomendaciones iniciales que finalmente fueron adoptadas, una ambiciosa apertura recíproca para el comercio de bienes, servicios e inversión que permita modernizar la relación comercial y potenciar el actual sistema regulatorio en vigor. Las negociaciones habrían de concentrarse en tres ámbitos primordiales: acceso a mercados; asuntos regulatorios y barreras no arancelarias; y la creación de reglas y principios de cooperación que hagan frente a los nuevos retos en el comercio mundial. ${ }^{20}$

De este modo se fijaron los principales objetivos que guían las negociaciones del TTIP. El conjunto de instancias que las negociaciones de este acuerdo mega-regional pretenden cubrir son:

— agilización de aduanas y facilitación del comercio;

- disminución de las barreras impuestas al comercio;

- políticas de fomento a la competencia;

- regulaciones para la subvención de empresas estatales y otras empresas que se benefician de derechos especiales;

- liberalización de los mercados de materias primas y energía;

— ampliación de la participación de las pequeñas y medianas empresas en el comercio internacional;

- transparencia en el régimen comercial regulatorio en vigor; $y$

- la creación de reglas en ámbitos como la propiedad intelectual, el medioambiente y el sector laboral. ${ }^{21}$

Las negociaciones del TTIP comenzaron de lleno en junio de 2013, después de que el presidente Obama informara al Congreso de los Estados Unidos su disposición de negociar el acuerdo. La Comisión Europea, que tiene la competencia para negociar acuerdos comerciales en representación de la Unión Europea, presentó a

${ }^{20}$ Grupo de Alto Nivel sobre Empleo y Crecimiento Económico, Reporte Final, 11 de febrero de 2013, http://trade.ec.europa.eu/doclib/docs/2013/february/ tradoc_150519.pdf (04/02/2016).

21 Ibid., p. 6. 
los Estados miembros sus directivas de negociación en julio de 2013. En este documento se destaca el objetivo de alcanzar un acuerdo ambicioso que "supere los estándares establecidos por la омc". ${ }^{22}$

El TTIP ha sido diseñado para ir más allá de los compromisos alcanzados en la омc, especialmente en lo que compete a servicios, cooperación regulatoria, adquisiciones públicas, protección de propiedad intelectual e inversión. ${ }^{23} \mathrm{El}$ acceso recíproco a los mercados de las Partes no deja de ser importante, sobre todo en lo que corresponde a servicios y regulación de establecimientos comerciales; sin embargo, la mayor innovación del TTIP radica en la armonización regulatoria, la facilitación de inversión y, potencialmente, el reconocimiento regulatorio mutuo.

La primera ronda de negociación tuvo lugar en Washington, D. C., en julio de 2013. Desde entonces han tenido lugar once rondas de negociación, lideradas por Dan Mullaney, jefe negociador por Estados Unidos, e Ignacio García Becerro, jefe negociador por la Unión Europea. ${ }^{24}$ A lo largo de las rondas de negociación, las Partes han evaluado la cooperación regulatoria, considerada como el pilar del acuerdo, así como la apertura de mercados para bienes. De acuerdo con los jefes negociadores, ambas partes han presentado sus propuestas y actualmente evalúan en conjunto el alcance de la compatibilidad regulatoria y el lenguaje que se incluirá en el tratado. ${ }^{25}$

${ }^{22}$ Comisión Europea, Directivas para la negociación del TTIP entre la UE y EE. UU., 17 de junio de 2013, p. 3.

${ }^{23}$ A manera de ejemplo, vale considerar la siguiente afirmación de la Unión Europea en la décima ronda de negociaciones del TTIP: "El sector de servicios es un componente fundamental de la economía transatlántica y por ende es un área en que la Unión Europea y Estados Unidos pretenden alcanzar compromisos ambiciosos que excedan aquellos hasta ahora alcanzados en otros acuerdos bilaterales y multilaterales" [énfasis de los autores]. Véase Comisión Europea, Ronda 10 del TTIP: Declaración del Jefe Negociador de la Unión Europea Ignacio García Bercero, Bruselas, 17 de julio de 2015, p. 1.

24 Oficina del Representante Comercial de los Estados Unidos, "Anuncios sobre las Rondas de Negociación del TTIP", https://ustr.gov/trade-agreements/ free-trade-agreements / transatlantic-trade-and-investment-partnership/readouts $(06 / 06 / 2015)$.

${ }^{25}$ Oficina del Representante Comercial de los Estados Unidos, "Declaracio- 
Debido a la importancia que mantiene para el marco general del acuerdo, los negociadores se han concentrado en la armonización de asuntos regulatorios y las reglas aplicables al comercio. Las discusiones en relación al sector de servicios aún no arrojan resultados en las negociaciones. Los negociadores se encuentran contrastando las respectivas propuestas de sus contrapartes, mismas que fueron presentadas en julio de $2015 .{ }^{26}$ Pese a ello, las discusiones han avanzado en paralelo para el resto de las áreas a negociar, incluyendo:

acceso a mercados (agricultura, comercio de bienes, compras públicas);

ámbito regulatorio (acuerdo de medidas sanitarias y fitosanitarias, obstáculos técnicos al comercio y coherencia regulatoria para los sectores automotriz, químico, farmacéutico, equipo médico, cosméticos, textiles, tecnologías de la información y la comunicación, sector de ingeniería, y pesticidas);

reglas (administración de aduanas y facilitación del comercio, derechos de propiedad intelectual, sistema de información geográfica, pequeñas y medianas empresas, solución de controversias, energía y materias primas). ${ }^{27}$

La primacía de la armonización regulatoria y las reglas aplicables al sector de servicios en el TTIP derivan de la realidad actual en el intercambio económico bilateral. Las importaciones de productos entre la Unión Europea y Estados Unidos son evaluadas a la tasa

nes de Apertura de los Jefes Negociadores del TTip en la Séptima Ronda de Negociaciones", octubre de 2014, https://ustr.gov/about-us/policy-offices/press-office /speeches / 2014/October/Opening-Remarks-by-US-and-EU-Chief-Negotiatorsfor-TTIP-Round-Seven-Press-Conference (06/06/2015).

${ }^{26}$ En la más reciente ronda de negociación, en octubre de 2015 , el jefe negociador de la Unión Europea refirió que aún se encuentran en proceso de revisión de posiciones en el sector de servicios, por lo que todavía es poco claro qué estructura tomará el acuerdo en este rubro. Véase Comisión Europea, “TTIP Ronda 11: Declaración del Jefe Negociador de la UE Ignacio García Bercero”, Miami, octubre de 2015, p. 1, http://trade.ec.europa.eu/doclib/docs/2015/october/tradoc_153910.pdf (03/12/2015).

27 Comisión Europea, "Reporte de la Novena Ronda de Negociación del TTIP”, 24 de abril de 2015, http://trade.ec.europa.eu/doclib/docs/2015/may/ tradoc_153437.pdf 
arancelaria de nación más favorecida o de relaciones comerciales normales y permanentes. ${ }^{28}$ Esto supone que los aranceles aplicables para los productos intercambiados por ambas partes son relativamente bajos. El arancel promedio simple ad valorem aplicado por Estados Unidos para los productos europeos es de 3.5 , mientras que aquel aplicado por la Unión Europea a productos estadounidenses es de $5.5 \% .^{29}$

Lo anterior no supone que las negociaciones sobre las tasas arancelarias carezcan de relevancia. ${ }^{30}$ Pese a las bajas tasas arancelarias promedio, ambas partes aún aplican altas tasas arancelarias en algunos sectores, tales como productos lácteos, azúcares y artículos de confitería, bebidas y tabaco, pescado y sus productos derivados, así como textiles y confección. Esta lista es encabezada, dada su importancia estratégica, por el conjunto de los productos agrícolas, para los que tanto la Unión Europea como Estados Unidos aplican aranceles máximos muy altos, alcanzando hasta $14 \%$ en algunos casos, si bien $40 \%$ del comercio agrícola está exento de aranceles. ${ }^{31}$

Las prescripciones que queden plasmadas en el TTIP regularán la relación comercial más relevante en el sistema de comercio mundial. Asimismo, estos principios fungirán como las bases de futuros acuerdos comerciales que tanto Estados Unidos como la Unión Europea firmarán con terceros países en el futuro. Lo que es más, se espera que este modelo sirva como plataforma para la negociación de acuerdos plurilaterales entre el resto de los países en el porvenir. De ahí la importancia de comprender a fondo la

${ }^{28}$ Mientras que los acuerdos internacionales utilizan el término "nación más favorecida", la legislación estadounidense ha optado por aquel de "relaciones comerciales normales y permanentes".

${ }^{29}$ омс, "Tariff Download Facility", 2015, http://tariffdata.wto.org/ReportersAndProducts.aspx

${ }^{30}$ De acuerdo con la regulación de la omc (art. Xxiv (8) (B) del GATT), los acuerdos de libre comercio deben eliminar los aranceles en "prácticamente todo el comercio".

${ }^{31}$ Véase Shayerah Ilias Akhtar y Vivian C. Jones, "Transatlantic Trade and Investment Partnership (TTIP) Negotiations", Congressional Research Service, febrero de 2014, R43387, p. 12; Eric Hayes, “TTIP: Transatlantic Free Trade at Last?”, Global Affairs, vol. 2, núm. 1, 2015, p. 115. 
estructura, los objetivos y las normas que actualmente son discutidas en las negociaciones del TTIP.

\section{HACIA UN MODELO DE LIBRE COMERCIO PARA EL SIGLO XXI}

Esta sección analiza algunas de las áreas de mayor relevancia que integrarán el TTIP, así como sus potenciales efectos. ${ }^{32}$ Estas regulaciones tendrán enorme importancia no sólo para Estados Unidos y la Unión Europea, sino también para el resto del mundo. Dado que se estima que el TTIP se convierta en un nuevo estándar para la negociación de acuerdos comerciales en el siglo XXI, sus prescripciones serán cruciales para la evolución del sistema comercial multilateral.

Las expectativas apuntan a que el potencial económico del TTIP excederá las ganancias de cualquier acuerdo de libre comercio firmado por Estados Unidos en el pasado, dado el tamaño y la naturaleza de las partes negociantes. Esto incluye al TPP, que, en caso de ratificarse y entrar en vigor, portará una tremenda importancia para la economía mundial.

En términos de comercio de bienes, el TTIP se convertiría en el tercer mayor acuerdo de libre comercio firmado por Estados Unidos, después del TPp y el Tratado de Libre Comercio de América del Norte (TLCAN). En términos de intercambio de servicios, el TTIP se convertiría en el mayor acuerdo de libre comercio firmado por Estados Unidos y la Unión Europea. Al tomar en cuenta ambos, bienes y servicios, el TTIP se convertiría en el tercer mayor acuerdo de libre comercio de Estados Unidos, tras el TPP y el TLCAN. ${ }^{33}$

${ }^{32}$ A razón de limitaciones de extensión, el texto se concentra en los sectores cuyo impacto económico se prevé tendrá mayor dimensión, sin menoscabo de otros ámbitos que serán de gran relevancia, como el sector aeroespacial o de servicios financieros, por nombrar sólo algunos.

${ }^{33}$ Shareyah Ilias Akhtar y Vivian C. Jones, "Proposed Transatlantic Trade and Investment Partnership (TTIP): In Brief", Congressional Research Service, junio de 2014, R43158, p. 9. 
Un ámbito que es importante destacar radica en el sector de inversiones, que también será incluido en el TTIP. En términos de inversión, el TTIP tiene el potencial de superar cualquier otro acuerdo de libre comercio firmado en la historia. La inversión entre Estados Unidos y la Unión Europea es casi seis veces mayor que aquella entre los socios del TLCAN, y cerca de tres veces mayor que aquella entre Estados Unidos y los países que integran el TPP. La Unión Europea es el principal inversionista en Estados Unidos, mientras que Estados Unidos es el país que más invierte en la Unión Europea. ${ }^{34}$

Pese a lo anterior, se ha proyectado que las mayores ganancias del TTIP para ambas partes serán producto de la reducción de las barreras no arancelarias al comercio. Estudios especializados en la materia apuntan a que cerca de dos terceras partes de los efectos económicos del TTIP serán resultado de la armonización regulatoria que reducirá las barreras no arancelarias entre Estados Unidos y la Unión Europea. ${ }^{35}$ Por tal razón se calcula que cerca de $80 \%$ de las negociaciones de este acuerdo se concentrarán en la armonización regulatoria. ${ }^{36}$

Las barreras no arancelarias y las divergencias regulatorias pueden tener dos efectos principales en las economías. Por un lado, pueden incrementar el costo de hacer negocios para las empresas, mientras que por otro tienen el potencial de restringir el acceso al mercado para estas. Ambos efectos pueden incidir de manera distinta, ya sea alterando la concentración de mercado artificialmente o trastornando el poder económico, y por ende la rentabilidad, de las empresas. De ahí la importancia para el sector empresarial de que el TTIP fomente la armonización regulatoria. ${ }^{37}$

${ }^{34}$ Shayerah Ilias Akhtar y Vivian C. Jones, "Transatlantic Trade and Investment Partnership (TTIP) Negotiations", Congressional Research Service, febrero de 2014, R43387, p. 12.

35 Comisión Europea, Transatlantic Trade and Investment Partnership: The Regulatory Part, septiembre de 2013, p. 2.

${ }^{36}$ Lucian Cernat y Nuno Sousa, “TTIP: A Transatlantic Bridge for Worldwide Gains”, Ces-Ifo Forum, núm. 2, 2014, Ces-Ifo Group Munich, p. 32.

${ }^{37}$ La cooperación regulatoria requiere ir más allá de acuerdos jurídicamente vinculantes (es decir, legalmente aplicable) entre Estados y hacia un esfuerzo de 
Se ha estimado que cerca de $60 \%$ del impacto de las barreras no arancelarias emana del encarecimiento de bienes y servicios, mientras que el restante $40 \%$ es consecuencia de la búsqueda de rentas (rent-seeking) por parte de algunas empresas. En ambos casos los efectos tienen repercusiones negativas tanto para la sociedad como para el sector empresarial, a consecuencia de las ineficiencias económicas creadas. ${ }^{38}$

Cabe enfatizar que la eliminación de barreras regulatorias es un proceso en extremo complejo y generalmente prolongado. En el contexto del TTIP será imposible lograr una completa armonización regulatoria (aunque existe el potencial de reconocimiento mutuo en algunos sectores). ${ }^{39}$ Existen múltiples causas de estas discrepancias regulatorias, muchas de las cuales provienen directamente de prescripciones constitucionales o cambios tecnológicos poco viables, ${ }^{40}$ sin mencionar las dificultades derivadas tanto de las maniobras de resistencia de los productores como de las preferencias de los consumidores.

Pese a lo anterior, es imperativo que ambas partes realicen un esfuerzo por minimizar las barreras no arancelarias actualmente aplicables. De acuerdo con un estudio, eliminar las barreras no

gobernanza. De ahí que se llame al acuerdo un "acuerdo viviente" (living agreement), dado que la regulación habrá de ser dinámica y, por ende, ajustable. La base para las negociaciones del TTIP en este sentido será el Acuerdo Integral de Economía y Comercio firmado por Canadá y la Unión Europea en 2014. Véase Bernard Hoekman, "Fostering Transatlantic Regulatory Cooperation and Gradual Multilateralization", Journal of International Economic Law, vol. 18, 2015, p. 613.

${ }^{38}$ Joseph Francois, op. cit., p. 16.

${ }^{39} \mathrm{Al}$ término de la undécima ronda de negociación del acuerdo, la Unión Europea comunicó que sus negociaciones en el rubro regulatorio se guiarán por dos principios: 1) el nivel de protección regulatoria para los ciudadanos no podrá disminuir (es decir, las regulaciones en vigor son un mínimo a partir del cual se negocia); y 2) las prescripciones en el tratado no podrán contravenir las regulaciones de políticas públicas (como en privacidad de datos o seguridad sanitaria) actualmente aplicables en la Unión Europea. Véase Comisión Europea, TTIP Ronda 11: Declaración del Jefe Negociador de la Unión Europea Ignacio García Bercero, pp. 1-2.

40 T. Sandra Fung, "Negotiating Regulatory Coherence: The Costs and Consequences of Disparate Regulatory Principles in Transatlantic Trade and Investment Partnership Agreement between the United States and the European Union”, Cornell International Law Journal, vol. 47, núm. 2, 2014, p. 459. 
arancelarias y regulatorias entre la Unión Europea y Estados Unidos en $50 \%$ potenciaría el PIB de la Unión Europea en 158000 millones de dólares anuales hacia 2018, mientras que generaría 53000 millones de dólares anuales adicionales en el PIB de Estados Unidos. ${ }^{41}$

El análisis econométrico más completo en la actualidad ha estimado, mediante el uso de un modelo de Equilibrio General Computable (CGE), que el proceso de convergencia regulatoria entre Estados Unidos y la Unión Europea beneficiaría a todos los sectores de ambas economías. Los sectores que recibirían mayores beneficios en la Unión Europea son aquellos de vehículos motorizados, químicos, cosméticos, farmacéuticos, alimentos y bebidas, y maquinaria eléctrica. Del mismo modo, aquellos sectores de la economía estadounidense que más se verían beneficiados por la armonización regulatoria son el de maquinaria eléctrica, servicios de seguros, servicios financieros, químico, cosmético y farmacéutico. ${ }^{42}$

Otros análisis son consistentes en cuanto a los sectores estratégicos en las negociaciones de la armonización regulatoria, señalando como prioritarios a los sectores químico, farmacéutico y automotriz. ${ }^{43}$ En el caso de los primeros dos sectores, existe un debate sobre si las partes deben trabajar en conjunto para perfeccionar los estándares regulatorios que serán aplicables, o si es preferible que estos se reduzcan al mínimo común denominador aplicable para ambos. ${ }^{44}$

En el sector farmacéutico existen complejidades adicionales que dificultan las negociaciones. Las empresas farmacéuticas estadounidenses destacan que existe una gran discrepancia en las regulaciones aplicables para los protocolos de investigación, manejo de

41 ECORYs, Non-Tariff Measures in EU-US Trade and Investment - An Economic Analysis, diciembre de 2009, p. xIx.

42 Ibid., p. XXII.

43 Shayerah Ilias Akhtar y Vivian C. Jones, "Transatlantic Trade and Investment Partnership (TTIP) Negotiations", Congressional Research Service, febrero de 2014, R43387, p. 24.

${ }^{44}$ Stormy Mildner y Oliver Ziegler, “A Long and Thorny Road: Regulatory Cooperation under the Framework for Advancing Transatlantic Economic Integration”, Intereconomics, núm. 44, enero-febrero de 2009, p. 53. 
información clínica y certificación de procesos en cada país de la Unión Europea. En contraste, los países de la Unión Europea a menudo critican los procesos aplicados por la Agencia de Alimentos y Medicamentos de Estados Unidos, así como las regulaciones medioambientales y de protección al consumidor en vigor en ese país. ${ }^{45}$ Lograr un acuerdo que satisfaga a ambas partes será altamente complejo; sin embargo, la comunidad empresarial ha expresado que el planteamiento presentado por los negociadores tiene un gran potencial para disminuir las duplicaciones regulatorias en beneficio de ambos, consumidores y productores. ${ }^{46}$

Es ampliamente aceptado que el sector más beneficiado de la armonización regulatoria propuesta por el TTIP sería el automotriz, con algunos escenarios que apuntan a una expansión de $43 \%$ en el comercio transatlántico en tal sector en caso de que se concluya el acuerdo. ${ }^{47}$ Esta expansión sería producto, en buena medida, de la armonización de los requerimientos para partes y componentes, así como aquellos relativos a la seguridad de los vehículos. ${ }^{48}$ Esto cobra enorme importancia si se considera que, de concluirse, el TTIP regularía más de un tercio del comercio automotriz mundial. ${ }^{49}$

Las barreras no arancelarias en el sector automotriz, producto de las discrepancias en los ámbitos mencionados, afectan a $34 \%$ de las exportaciones de la Unión Europea a Estados Unidos y $31 \%$ de aquellas originarias de Estados Unidos con destino a la Unión Europea. ${ }^{50}$ Se estima que las barreras no arancelarias, como

45 Comité de Política Comercial de los Estados Unidos, Audiencia Pública sobre el TTIP, 29 de mayo de 2013, citado en Shayerah Ilias Akhtar y Vivian C. Jones, "Transatlantic Trade and Investment Partnership (тTIP) Negotiations", Congressional Research Service, febrero de 2014, R43387, p. 24.

46 Audiencia del Comité de Finanzas del Senado de los Estados Unidos, The Transatlantic Trade and Investment Partnership: Achieving the Potential, Primera sesión, $103^{\circ}$ Congreso, 30 de octubre de 2013, p. 10.

${ }^{47}$ Joseph Francois, op. cit., p. 65.

48 Raymond J. Ahearn, Transatlantic Regulatory Cooperation: Background and Analysis, Congressional Research Service, agosto de 2014, RL34717, p. 3.

${ }^{49}$ Parlamento Europeo, Dirección General para Políticas Internas, TTIP: Challenges and Opportunities for the Internal Market and Consumer Protection in the Area of Motor Vehicles, julio de 2015, p. 7.

${ }^{50}$ Joseph Francois, op. cit., p. 110. 
regulaciones y estándares técnicos, así como procesos de evaluación y conformidad, suponen el equivalente al costo de un arancel promedio de $26 \%$ en ambos lados del Atlántico. ${ }^{51}$ De ahí que la industria automotriz apoye la inclusión de un acuerdo de reconocimiento mutuo en el TTIP. ${ }^{52}$ Dicho acuerdo no sólo reduciría los costos para la industria, sino que también permitiría a los consumidores contar con una mayor gama de alternativas de vehículos.

Pese al apoyo de la industria, identificar las barreras no arancelarias que distorsionan el comercio en el sector automotriz es una tarea compleja. A esta problemática se suman las discrepancias en los estándares de seguridad y ambientales entre ambas partes. ${ }^{53}$ De estos, los primeros serán menos complejos de manejar que los segundos. En el caso de estándares de seguridad, existen similitudes en ambos marcos regulatorios y la principal diferencia -mitigable- radica en el ámbito de supervisión de pruebas de seguridad. ${ }^{54}$ En el caso ambiental, la complejidad es mayor, ya que las regulaciones y los estándares de emisiones son notablemente disímiles.

De cualquier forma, el panorama en el sector automotriz es aliciente. En caso de que se logre la armonización regulatoria, el comercio automotriz bilateral podría expandirse $20 \%$, con que

${ }^{51}$ Parlamento Europeo, Dirección General para Políticas Internas, TTIP: Challenges and Opportunities for the Internal Market and Consumer Protection in the Area of Motor Vehicles, julio de 2015, p. 20.

52 Shayerah Ilias Akhtar y Vivian C. Jones, "Transatlantic Trade and Investment Partnership (TTIP) Negotiations", Congressional Research Service, febrero de 2014, R43387, p. 24.

${ }^{53}$ Parlamento Europeo, Dirección General para Políticas Internas, TTIP: Challenges and Opportunities for the Internal Market and Consumer Protection in the Area of Motor Vehicles, p. 21.

${ }^{54}$ Las regulaciones en los Estados Unidos y la Unión Europea llevan a niveles de seguridad automotriz prácticamente idénticos. Un automóvil considerado seguro en Estados Unidos también debería serlo en la Unión Europea, y viceversa. En este sentido, lo más viable (siendo, además, la posición negociadora de la Unión Europea) es que se logre el reconocimiento mutuo del mayor número de regulaciones posibles. En aquellos casos en que no sea posible, se considera oportuno optar por la armonización. 
resultara en ganancias de 20000 millones de dólares. ${ }^{55}$ De acuerdo a un estudio reciente, será posible resolver entre 42 y $48 \%$ de las divergencias regulatorias. ${ }^{56}$ Esto se debe en gran medida al apoyo de la industria automotriz al TTIP. El comercio automotriz transatlántico es mayoritariamente intra-firma. La mayor parte del comercio de vehículos automotores, de pasajeros y autopartes tiene lugar en el interior de grandes empresas, como General Motors, por nombrar sólo una.

Un sector más en el que el proceso de negociación es controversial es aquel de los organismos genéticamente modificados (OGM). Se trata de un segmento económicamente significativo para ambas partes y en el que las políticas regulatorias resaltan por su discordancia. Estados Unidos es el mayor productor de cultivos genéticamente modificados en el mundo, mientras que la Unión Europea ha bloqueado el cultivo y la importación de dichos productos recurrentemente. ${ }^{57}$

Estados Unidos ha regulado el sector de los OGM bajo un régimen de enfoque preventivo. ${ }^{58}$ En este régimen resulta irrelevante si un producto es o no genéticamente modificado siempre y cuando

55 Caroline Freund y Sarah Oliver, Gains from Harmonizing US and EU Auto Regulations under the Transatlantic Trade and Investment Partnership, Peterson Institute for International Economics, Policy Brief no. PB15-10, junio de 2015, p. 17. Otro estimado de la Comisión Europea asegura que la eliminación de las barreras al comercio en el sector podría aumentar el comercio automotor entre Estados Unidos y la Unión Europea entre 70 y $350 \%$ en el periodo 2017-2027. Véase Comisión Europea, Vehicles in TTIP, enero de 2015, http://trade.ec.europa.eu/doclib/ docs/2015/january/tradoc_153012.4.9\%20Vehicles.pdf (02/12/2015).

${ }^{56}$ Parlamento Europeo, Dirección General para Políticas Internas, TTIP: Challenges and Opportunities for the Internal Market and Consumer Protection in the Area of Motor Vehicles, p. 23.

${ }^{57}$ Para un análisis a fondo, véase Diahanna Lynch y David Vogel, “The Regulation of ogms in Europe and the United States: A Case Study of Contemporary European Regulatory Politics”, Council on Foreign Relations, abril de 2001.

${ }^{58}$ Para un tratamiento a detalle de las discrepancias regulatorias en el sector de organismos genéticamente modificados y sus implicaciones para el TTIP, véase Carolyn M. Dudek, "Rhetoric and Reality: The Trade Challenge of Genetically Modified Organisms", en Joaquín Roy y Roberto Domínguez (eds.), The TTIP: The Transatlantic Trade and Investment Partnership between the European Union and the United States, Universidad de Miami, 2014, pp. 111-124. 
mantenga una equivalencia sustancial con el mismo producto de origen natural en su estado final. Las agencias reguladoras en Estados Unidos no someten a los OGM a un proceso de inspección distinto a aquel al que someten a sus pares naturales. Cuando surgen inspecciones adicionales en casos especiales, los procesos de sanidad se concentran en evaluar los riesgos actuales y no aquellos potenciales derivados del uso y producción de este tipo de productos.

La lógica reguladora en la Unión Europea sigue otra ruta. La Unión Europea considera que dado que los OGM atraviesan por un proceso de producción distinto que sus equivalentes naturales, estos deben ser sometidos a evaluaciones particulares. De ahí que la Unión Europea ha emitido regulación específica que evalúa y controla cualquier producto surgido, completamente o en parte, de oGM. Entonces, el proceso regulatorio se basa en un enfoque de precaución en el que el riesgo probable surgido de los OGM tiene prevalencia sobre el riesgo actual probado científicamente.

Un elemento que añade complejidad a la regulación en la Unión Europea deriva del poder de los Estados miembros de imponer restricciones aplicables en su territorio nacional. Así, incluso si las agencias de salubridad de la Unión Europea aprueban el cultivo y consumo de un ogM, cada Estado miembro mantiene la facultad de bloquear el uso y consumo del mismo en su territorio, recurriendo a la llamada "cláusula de seguridad". Esta cláusula congela la producción, venta y consumo de un OGM precisamente bajo el argumento de prevenir sus posibles efectos. ${ }^{59}$

Las incompatibilidades en los procesos de regulación en ambos lados del Atlántico han incitado disputas comerciales en el pasado, que llegan incluso a contenciosos mediados por la omc. Ya en septiembre de 2006, un panel de la omc falló a favor de Estados Unidos (Canadá y Argentina) al encontrar que las agencias reguladoras de la Unión Europea violaron el Acuerdo sobre la Aplicación

${ }^{59}$ En la actualidad, ocho países miembros de la Unión Europea han prohibido por completo el cultivo de organismos genéticamente modificados en su territorio: Austria, Bulgaria, Grecia, Alemania, Hungría, Italia, Luxemburgo y Polonia. Francia mantuvo la prohibición hasta 2013, cuando fue revocada por el Consejo de Estado. 
de Medidas Sanitarias y Fitosanitarias. ${ }^{60} \mathrm{El}$ panel concluyó que las agencias reguladoras de la Unión Europea aplicaron dilaciones indebidas en el proceso de evaluación y aprobación de organismos genéticamente modificados.

En el periodo entre 2001 y 2013, la Unión Europea no aprobó el cultivo de un solo tipo de ogm, implementando un proceso de moratoria que ocasionó numerosos contratiempos para la distribución de granos estadounidenses en Europa. En un claro cambio de curso, en agosto de 2015, en medio del proceso de negociación del TTIP, la Unión Europea aprobó la importación de diez cultivos genéticamente modificados para uso alimenticio animal y humano. De entre estos destacan diversos tipos de maíz, soja, algodón y colza oleaginosa que han sido producidos ampliamente en Estados Unidos y Asia por empresas como Monsanto, BASF y Bayer, entre otras. Con esto, el total de cultivos genéticamente modificados aprobados por la Unión Europea alcanzó un total de 54. ${ }^{61}$

La inclusión de organismos genéticamente modificados en el TTIP complica las negociaciones vinculadas a la agricultura y biotecnología. Las posiciones se encuentran en directa oposición y es poco factible que alguna de las partes ceda y adopte la posición de su contraparte. De manera similar, será complejo lograr una armonización de políticas, criterios y legislación, dado que Estados Unidos y la Unión Europea (y los países individuales que la conforman) tienen percepciones y estrategias disímiles -muchas veces enfrentadas unas con otras- en este tema en particular.

En el ámbito de la cooperación regulatoria en el TTIP, es de esperar que cada sector económico en negociación -incluidos los ya mencionados- adquiera alguna de tres modalidades: armonización, reconocimiento mutuo o equivalencia. ${ }^{62}$ La primera resulta la

${ }^{60}$ Oficina del Representante Comercial de los Estados Unidos, 2014 Report on Sanitary and Phytosanitary Measures, marzo de 2014, p. 45.

${ }^{61}$ La lista completa de cultivos genéticamente modificados que han sido aprobados por la Unión Europea se encuentra en: Comisión Europea, "Genetically Modified Organism: EU Register of Authorised oGMs”, 2015, http:/ / ec.europa. eu/food/dyna/gm_register/index_en.cfm (04/02/2016).

62 “Armonización” implica alinear las regulaciones en los países signatarios a una sola mejor práctica. El "reconocimiento mutuo" supone que si bien cada par- 
más conveniente, implicando que la misma regulación aplique en ambos lados del Atlántico; no obstante, existen sectores en los que esto será muy complicado de alcanzar. Una complicación adicional radica en la implementación y la administración de los acuerdos de armonización. Hasta el momento no es claro cómo serán supervisados, implementados y administrados estos acuerdos regulatorios. ${ }^{63}$

Como se mencionó, aunado a las medidas regulatorias, la inversión es un componente esencial en la arquitectura del TTIP. Este ámbito es fundamental en las negociaciones no sólo debido a la magnitud de los intercambios -actuales y prospectivos- sino también por las divergencias en las posturas de las partes, mismas que complicarán el proceso.

Estados Unidos negocia los acuerdos de inversión incluidos en tratados de libre comercio bajo un modelo de convenio bilateral de inversiones (BIT, por sus siglas en inglés). Este esquema incluye cinco características principales:

1. Contiene el trato no discriminatorio en inversiones, implementado mediante el mecanismo de trato nacional o nación más favorecida.

2. Establece límites claros para la expropiación de inversiones, así como previsiones para el pago de compensaciones en caso de expropiación.

3. Prescribe favorecer el movimiento de capitales de sus nacionales en el territorio de la contraparte y bajo tipo de cambio de mercado.

4. Instituye el mecanismo de arbitraje de diferencias Estadoinversor (ISDS, por sus siglas en inglés).

5. Fija restricciones en el uso de requisitos de desempeño que ocasionen distorsiones (por ejemplo, reglas de contenido nacional,

te mantiene sus propios estándares regulatorios, la contraparte reconoce los lineamientos aplicables como satisfactorios en su propia jurisdicción. "Equivalencia", una forma de reconocimiento mutuo, señala que las partes reconocen los procedimientos de verificación de estándares en sectores específicos.

63 Simon Lester e Inu Barbee, "The Challenge of Cooperation: Regulatory Trade Barriers in the Transatlantic Trade and Investment Partnership", Journal of International Economic Law, vol. 16, núm. 4, diciembre de 2013, p. 859. 
requerimientos de transferencia de tecnología o cuotas a la exportación) .64

Estados Unidos ya ha firmado tratados bilaterales de inversión bajo el modelo mencionado con algunos países de la Unión Europea: Eslovaquia (1992), República Checa (1992), Bulgaria (1994), Rumania (1994), Polonia (1994), Letonia (1996), Estonia (1997), Croacia (2001) y Lituania (2001). Sin embargo, como se evidencia, aún no existen tratados de esta naturaleza entre Estados Unidos y los grandes países inversionistas en Europa, como el Reino Unido, Alemania, Francia o España.

Los países miembros de la Unión Europea comparten los principios plasmados en el modelo BIт de Estados Unidos. En abril de 2012, la Unión Europea y Estados Unidos firmaron una declaración en la que reafirmaron su compromiso por asegurar un esquema de inversiones abierto, transparente y no discriminatorio. ${ }^{65}$ Más tarde, ambas partes reafirmaron una vez más su compromiso por liberalizar los flujos de inversión, así como asegurar la protección de las inversiones bilaterales y los inversionistas mediante mecanismos eficientes de solución de controversias. ${ }^{66}$

Así, tanto Estados Unidos como la Unión Europea comparten los mismos principios generales plasmados en el modelo de convenio bilateral de inversiones. ${ }^{67}$ La polémica se concentra en el

${ }^{64}$ Oficina del Representante Comercial de los Estados Unidos, 2012 U.S. Model Bilateral Investment Treaty, 2012, https://ustr.gov/sites/default/files/BIT\%20 text\%20for\%20ACIEP\%20Meeting.pdf (09/06/2015).

65 Statement of the European Union and the United States on Shared Principles for International Investment, abril de 2012, http://trade.ec.europa.eu/doclib/docs/ 2012/april/tradoc_149331.pdf (11/06/2015).

${ }^{66}$ Grupo de Alto Nivel sobre Empleo y Crecimiento Económico, Reporte Final, 11 de febrero de 2013, p. 1.

${ }^{67}$ Hay quienes han sugerido que si el objetivo del TTIP es mejorar el clima regulatorio para los inversores en Estados Unidos y la Unión Europea, posiblemente no sea del todo necesario proveer a inversionistas extranjeros con mecanismos de protección, como aquel de disputas Estado-inversor, en este acuerdo; sobre todo si se toma en cuenta que los BIT pueden regular este ámbito por cuenta propia. Es decir, se critica la inclusión de provisiones generalmente incluidas en los Bit en el TTIP. Véase Marise Cremona, "Negotiating the TTIP", Common Market Law Review, vol. 52, núm. 2, 2015, pp. 351-362. Otros han sugerido que el тTIP 
mecanismo de arbitraje de diferencias Estado-inversor. Este hecho resulta sorprendente dado que de los 3000 tratados bilaterales de inversión que existen en el mundo, todos los cuales incluyen mecanismos de arbitraje, casi la mitad han sido firmados por países que integran a la Unión Europea. ${ }^{68}$

La Comisión Europea realizó un estudio de opinión entre los países miembros de la Unión Europea y encontró que más de $97 \%$ de los encuestados se oponen a la inclusión del mecanismo de arbitraje de diferencias Estado-inversor en el TTIP. ${ }^{69}$ En consecuencia, la comisaria de Comercio de la Unión Europea, Cecilia Malmström, reconoció el escepticismo en Europa ante este mecanismo y las dificultades que implicará el tema en la negociación. ${ }^{70}$

La Comisión Europea ha expresado que las principales provisiones incluidas en el mecanismo de arbitraje de diferencias Estado-inversor que le preocupan son la falta de transparencia, las credenciales y conducta de los árbitros independientes, y la ausencia de un mecanismo de apelación. ${ }^{71}$

En relación a la transparencia, la postura de la Unión Europea es que todas las audiencias judiciales que surjan como resultado del mecanismo de arbitraje deberán ser públicas en su totalidad,

ofrece la oportunidad de poner coto a las inconsistencias que surgen a consecuencia de la proliferación de BIт, los cuales han fragmentado los criterios aplicables. Véase Reinhard Quick, "Why TTIP Should Have an Investment Chapter Including IsDs”, Journal of World Trade, vol. 49, núm. 2, 2015, p. 206.

68 Doak Bishop, "Investor-State Dispute Settlement under the Transatlantic Trade and Investment Partnership: Have the Negotiations Run Aground?”, ICSID Review 30, núm. 1, 2015, p. 2.

69 Comisión Europea, Online Public Consultation on Investment Protection and Investor-to-State Dispute Settlement (ISDS) in the Transatlantic Trade and Investment Partnership Agreement, 13 de enero de 2015, http://trade.ec.europa.eu/doclib/docs/ 2015/january/tradoc_153044.pdf (08/06/2015).

${ }^{70}$ Christian Olivier, "Public Backlash Threatens EU Trade Deal with the US", Financial Times, 13 de enero de 2015, http:/ /www.ft.com/intl/cms/s/0/8c17a17e-9 b33-11e4-882d-00144feabdc0.html\#axzz3cWMTui6X (08/06/2015).

${ }^{71}$ Comisión Europea, Public Consultation on Modalities for Investment Protection and Investor-to-State Dispute Settlement (ISDS) in the Transatlantic Trade and Investment Partnership Agreement, marzo de 2014, http://trade.ec.europa.eu/doclib/docs/ 2014/march/tradoc_152280.pdf (10/06/2015). 
incluyendo la publicación de documentos oficiales. ${ }^{72}$ Este acercamiento difiere de las prácticas internacionales y es de esperar que Estados Unidos presente resistencia al modelo, en parte por la presión de sus corporaciones.

La Unión Europea ha expresado que la conducta y los códigos de ética de los árbitros tienen enorme importancia. A la Unión Europea preocupan los conflictos de interés, dado que no es extraño que los árbitros tengan (o hayan tenido) alguna relación con las empresas demandantes. La propuesta de la Unión Europea en este sentido es establecer un código de ética para los árbitros en el tratado, algo inusual de acuerdo a estándares internacionales. El modelo a seguir es el Acuerdo Integral de Economía y Comercio entre Canadá y la Unión Europea (CETA, por sus siglas en inglés), firmado en 2014.

La tercera cuestión, el mecanismo de apelación, es aún más compleja. En la actualidad, todos los acuerdos bilaterales de inversión incluyen provisiones que otorgan a la decisión del tribunal en un mecanismo de arbitraje carácter de final. Esto implica que las partes involucradas en el proceso no tienen derecho a apelar la decisión. Hasta el momento no existe un acuerdo de inversiones entre dos países que incluya provisiones que permitan a las partes en un litigio hacer una apelación tras el veredicto del tribunal en el mecanismo de arbitraje. Eso es precisamente lo que la Unión Europea desea integrar al TTIP. ${ }^{73}$ La estructura y el funcionamiento de este mecanismo aún no se conocen en detalle, aunque han surgido algunas discusiones sobre sus potenciales consecuencias y costos. ${ }^{74}$

${ }^{72}$ La propuesta de la Unión Europea para el capítulo de protección de inversiones y el sistema del tribunal de inversiones se ha hecho pública. Véase Unión Europea, "Capítulo 2: Inversiones", en TTIP: Trade in Services, Investment and E-Commerce, 12 de noviembre de 2015, http://trade.ec.europa.eu/doclib/docs/2015/ november/tradoc_153955.pdf (03/12/2015).

${ }^{73}$ Comisión Europea, Investment in TTIP and Beyond - the Path to Reform: Enhancing the Right to Regulate and Moving from Current Ad Hoc Arbitration towards and Investment Court, mayo de 2015, http://trade.ec.europa.eu/doclib/docs/2015/ may/tradoc_153408.PDF (11/06/2015).

${ }^{74}$ Lauge N. Skovgaard Poulsen, Jonathan Bonnitcha, Jason Webb Yackee, Costs and Benefits of an EU-USA Investment Protection Treaty, London School of Economics, abril de 2013; Lauge Paulsen, Jonathan Bonnitcha y Jason Yackee, Transat- 
Quienes se oponen al mecanismo de arbitraje de diferencias Estado-inversor arguyen que es una amenaza para la democracia, soberanía, finanzas públicas y políticas públicas de cada país. Este grupo percibe, además, que el mecanismo es riesgoso, pues nada asegura la imparcialidad y objetividad de los árbitros. En contraste, quienes apoyan el mecanismo, en su mayoría empresas y asociaciones de empresarios, argumentan que el mecanismo provee certidumbre a los inversionistas y promueve reglas equitativas, lo que potencia los intercambios de inversión. ${ }^{75}$

Una de las explicaciones de la disparidad en la percepción del mecanismo de arbitraje de diferencias Estado-inversor propone que éste ha sido mucho más politizado en Estados Unidos, mientras que en Europa se trata de un fenómeno relativamente reciente. Desde las discusiones que precedieron al TLCAN, el mecanismo de arbitraje de diferencias Estado-inversor ha abierto amplios debates en Estados Unidos, con que crea una gran conciencia sobre su funcionamiento y gana en la mayoría de los casos el apoyo de las empresas multinacionales. ${ }^{76}$

Una complicación adicional deriva de la inclusión de la Unión Europea como parte firmante del capítulo de inversión en el TTIP y su consecuente papel en un proceso de arbitraje. Surge así la pregunta de si en caso de una disputa legal en materia de inversión es la Unión Europea o directamente el país miembro involucrado

lantic Investment Treaty Protection, Center for European Policy Studies/Johns Hopkins University, Reporte 102, marzo de 2015; Freya Baetens, Transatlantic Treaty Investment Protection - A Response to Poulsen, Bonnitch a and Yackee, Center for European Policy Studies/Johns Hopkins University, Reporte 103, marzo de 2015; Markus Krajewski, Modalities for Investment Protection and Dispute Settlement (ISDS) in TTIP from a Trade Union Perspective, Friedrich Ebert Stiftung, noviembre de 2014; Mark Weaver, "The Proposed Transatlantic Trade and Investment Partnership (TTIP): IsDs Provisions, Reconciliation, and Future Trade Implications", Emory International Law Review, vol. 29, 2014, pp. 225-275.

75 Comisión Europea, Online Public Consultation on Investment Protection and Investor-to-State Dispute Settlement (ISDS) in the Transatlantic Trade and Investment Partnership Agreement, p. 14.

${ }^{76}$ Lauge Poulsen, Jonathan Bonnitcha y Jason Yackee, Transatlantic Investment Treaty Protection, Center for European Policy Studies/Johns Hopkins University, Reporte 102, marzo de 2015, p. 9. 
quien debe responder. Esta disyuntiva fue examinada desde 2012 por la Unión Europea con el objetivo de alcanzar una postura final. De acuerdo con la postura acordada, la Unión Europea actuaría como responsable siempre que sus intereses, o aquellos de sus instituciones, sean los primordialmente afectados por la disputa de arbitraje. Así, la regulación actual muestra la disposición de hacer de la Comisión Europea el principal actor en el proceso de arbitraje por inversiones. ${ }^{77}$

Finalmente, persiste el debate sobre si es necesario incluir el mecanismo de diferencias Estado-inversor en el TTIP, considerando que las partes negociantes son países desarrollados. Tradicionalmente los países de ingresos altos no concluyen acuerdos que incluyan este tipo de mecanismos. Esto es así dado que las contrapartes por lo común reconocen que el sistema legal doméstico de cada país ofrece suficiente protección a los inversionistas, haciendo el acuerdo de arbitraje innecesario. Tal es la postura actual de Alemania, que por dicha razón no apoya la inclusión de un mecanismo de arbitraje Estado-inversor en el TTIP. ${ }^{78}$

La negociación en torno al capítulo relacionado a la inversión del TTIP será contenciosa. Su importancia para el éxito del tratado es angular, dada la primacía de los intercambios de inversión en la relación económica entre Estados Unidos y la Unión Europea. Aún no se tiene claridad sobre los pormenores de las regulaciones sobre inversiones mutuas que se incluirán en el TTIP. Empero, es asequible que en algún momento se incluya el mecanismo de diferencias Estado-inversor, bien arraigado en la práctica internacional, pese a la resistencia que tal hecho podría enfrentar en algunos sectores de la Unión Europea.

Como se ha mencionado en esta sección, las negociaciones sobre los mecanismos de armonización regulatoria y de manejo de disputas de inversión tienen un papel central en las negociaciones del тTіP. La evolución que tenga lugar en estos rubros será,

77 Roland Klager, "The Impact of TTIP on Europe's Investment Arbitration Architecture", Law Journal of the German - American Lawyers Association, núm. 2, 2014, p. 73.

78 Ibid., p. 72. 
por encima de las negociaciones arancelarias, determinante para el futuro del tratado. Será, asimismo, un punto elemental para la evolución de las negociaciones comerciales a futuro, así como la estructura y el funcionamiento de los acuerdos de libre comercio del siglo XXI.

\section{Conclusión}

El TTiP se originó a razón de la búsqueda de Estados Unidos y la Unión Europea por mantener, e incluso expandir, su poderío en el sistema económico internacional, sobre todo a la luz de los cambios que derivan del ascenso de nuevas potencias emergentes, como China y la India, por nombrar algunas. Los cambios en la estructura de la producción mundial han orillado a Estados Unidos a plantear una estrategia que le permita continuar determinando aquellas reglas que habrán de regular los principales flujos comerciales en las próximas décadas. De ahí que Estados Unidos lleve a cabo notorios esfuerzos para culminar acuerdos comerciales con el potencial de colocarlo en el centro de los principales flujos económicos mundiales en el futuro.

La consumación del TTIP habrá de afectar no sólo los intercambios económicos entre las partes involucradas, sino también aquellos de Estados Unidos y la Unión Europea con el resto de sus socios comerciales. Asimismo, como se ha mencionado, es asequible que el modelo utilizado en la negociación y formulación del TTIP -en conjunto con aquel del TPP- se convierta en el estándar que rija aquellos acuerdos comerciales que se firmen en el porvenir.

El TTIP tiene, además, la capacidad de poner fin al letargo que ha permeado al sistema de comercio multilateral a consecuencia de la parálisis de la Ronda de Doha. La negociación de reglas comerciales fuera de los auspicios de la омc es un riesgo que muchos han señalado, y con razón. Con todo, esta misma estrategia podría tener repercusiones positivas, motivando al resto de la comunidad internacional a avanzar en la formulación de reglas que continúen facilitando el comercio internacional. 
Aunado a esto, no es improbable que el TTIP (y el TPP) transforme los estándares estructurales de los acuerdos comerciales internacionales. La primacía de la armonización regulatoria es preludio de las complejidades que los países que se embarquen en futuras negociaciones comerciales tendrán que asumir de manera creciente. Las normas y los modelos que asienten el тTIP y el трP sin duda permearán en futuros acuerdos. Esto es de especial trascendencia para sectores cuya centralidad en este tipo de convenios irá en aumento, incluidos aquellos mencionados en este artículo, como la regulación de productos farmacéuticos y biotecnológicos. La necesidad de que los países coordinen sus políticas comerciales, y aquellas de ciencia y tecnología, únicamente crecerá. La política comercial es, ahora más que nunca, parte de la política de fomento al desarrollo científico y tecnológico.

La nueva generación de acuerdos comerciales que han surgido en el mundo impulsados por Estados Unidos en años recientes -el TPP y el TTIP, esencialmente- ofrecen razones para mantener una visión positiva sobre los prospectos del comercio internacional. Tras años de un impasse cuya disolución parecía inverosímil, el surgimiento del nuevo paradigma comercial impulsado por Estados Unidos, y al que se ha sumado buena parte de las principales economías del mundo (con la notable ausencia de China y la India), tendrá efectos que habrá que observar y estudiar con detalle. Hasta ahora la evidencia señala a que la culminación del acuerdo analizado en este artículo (y su símil en la cuenca del Pacífico, el TPP) será piedra angular en el avenimiento de un manifiesto proceso de reestructuración del sistema global de comercio e inversiones.

\section{BibLIOGRAFÍA}

Ahearn, Raymond J., "Transatlantic Regulatory Cooperation: Background and Analysis", Congressional Research Service, agosto de 2014, RL34717.

Akhtar, Shayerah Ilias y Vivian C. Jones, "Transatlantic Trade and Investment Partnership (TTIP) Negotiations", Congressional Research Service, febrero de 2014, R43387. 
, "Proposed Transatlantic Trade and Investment Partnership (TTIP): In Brief”, Congressional Research Service, junio de 2014, R43158.

Baetens, Freya, Transatlantic Treaty Investment Protection - A Response to Poulsen, Bonnitcha and Yackee, Bruselas, Centre for European Policy Studies/Johns Hopkins University, cEPS Special Report 103, marzo de 2015.

Bishop, Doak, "Investor-State Dispute Settlement under the Transatlantic Trade and Investment Partnership: Have the Negotiations Run Aground?”, ICSID Review, 30, núm. 1, 2015, pp. 1-9.

Cernat, Lucian y Nuno Sousa, “TтIP: A Transatlantic Bridge for Worldwide Gains”, Ces-Ifo Forum, núm. 2, 2014, Ces-Ifo Group Munich, pp. 32-36.

Comisión Europea, "Reporte de la Novena Ronda de Negociación del TTIP”, 24 de abril de 2015, http://trade.ec.europa.eu/doclib/ docs/2015/may/tradoc_153437.pdf

, Vehicles in TTIP, enero de 2015, http://trade.ec.europa.eu/doclib/docs/2015/january/tradoc_153012.4.9 20Vehicles.pdf

—, Directivas para la Negociación del TTIP entre la UE y EE. UU, 17 de junio de 2013.

, "Investment in TTIP and Beyond - the Path to Reform: Enhancing the Right to Regulate and Moving from Current Ad Hoc Arbitration towards and Investment Court”, mayo de 2015, http://trade. ec.europa.eu/doclib/docs/2015/may/tradoc_153408.PDF

, "Online Public Consultation on Investment Protection and Investor-to-State Dispute Settlement (ISDS) in the Transatlantic Trade and Investment Partnership Agreement", 13 de enero de 2015, http://trade.ec.europa.eu/doclib/docs/2015/january/tradoc_15 3044.pdf

, "Public Consultation on Modalities for Investment Protection and Investor-to-State Dispute Settlement (ISDS) in the Transatlantic Trade and Investment Partnership Agreement”, marzo de 2014, http:/ / trade.ec.europa.eu/doclib/docs/2014/march/tradoc_1522 80.pdf

oGMs", 2015, http://ec.europa.eu/food/dyna/gm_register/index_ en.cfm 
, "Reporte de la Décimo Primer Ronda de Negociaciones del TTIP”, Miami, octubre de 2015.

— Unión Europea Ignacio García Bercero”, Bruselas, 17 de julio de 2015.

—, "Transatlantic Trade and Investment Partnership: The Regulatory Part”, septiembre de 2013.

— , “TTIP Ronda 11: Declaración del Jefe Negociador de la UE Ignacio García Bercero", Miami, octubre de 2015, http:/ / trade.ec.europa.eu/doclib/docs/2015/october/tradoc_153910.pdf

Comité de Finanzas del Senado de los Estados Unidos, "The Transatlantic Trade and Investment Partnership: Achieving the Potential", Primera sesión, $103^{\circ}$ Congreso, 30 de octubre de 2013.

Comité de Política Comercial de los Estados Unidos, "Audiencia Pública sobre el TTIP", 29 de mayo de 2013, citado en Shayerah Ilias Akhtar y Vivian C. Jones, "Transatlantic Trade and Investment Partnership (TTIP) Negotiations", Congressional Research Service, febrero de 2014, R43387.

Conferencia de las Naciones Unidas sobre Comercio y Desarrollo (UNCTAD), "Estadísticas sobre comercio internacional", junio de 2015.

Cremona, Marise, "Negotiating the TTIP", Common Market Law Review, vol. 52, núm. 2, 2015, pp. 351-362.

Dudek, Carolyn M., "Rhetoric and Reality: The Trade Challenge of Genetically Modified Organisms”, en Joaquín Roy y Roberto Domínguez (eds.), The TтIP: The Transatlantic Trade and Investment Partnership between the European Union and the United States, Universidad de Miami, 2014, pp. 111-124.

ECORYS, "Non-Tariff Measures in EU-US Trade and Investment - An Economic Analysis", Final Report, OJ 2007/S 180-219493, diciembre de 2009, http://trade.ec.europa.eu/doclib/docs/2009/december/tradoc_145613.pdf

Francois, Joseph, "Reducing Transatlantic Barriers to Trade and Investment: An Economic Assessment”, Londres, Centre for Economic Policy Research, marzo de 2013.

Freund, Caroline y Sarah Oliver, Gains from Harmonizing US and EU Auto Regulations under the Transatlantic Trade and Investment Partnership, 
Peterson Institute for International Economics, Policy Brief no. PB15-10, junio de 2015.

Fung, T. Sandra, "Negotiating Regulatory Coherence: The Costs and Consequences of Disparate Regulatory Principles in Transatlantic Trade and Investment Partnership Agreement between the United States and the European Union”, Cornell International Law Journal, vol. 47, núm. 2, 2014, pp. 445-471.

Grupo de Alto Nivel sobre Empleo y Crecimiento Económico, Reporte Final, 11 de febrero de 2013, http://trade.ec.europa.eu/doclib/ docs/2013/february/tradoc_150519.pdf

Hayes, Eric, “ттіP: Transatlantic Free Trade at Last?”, Global Affairs, vol. 2, núm. 1, 2015, pp. 113-120.

Hoekman, Bernard, "Fostering Transatlantic Regulatory Cooperation and Gradual Multilateralization", Journal of International Economic Law, vol. 18, 2015 , pp. 609-624.

Klager, Roland, "The Impact of TTIP on Europe's Investment Arbitration Architecture", Law Journal of the German - American Lawyers Association, núm. 2, 2014, pp. 68-73.

Krajewski, Markus, Modalities for Investment Protection and Dispute Settlement (ISDS) in TTIP from a Trade Union Perspective, Friedrich Ebert Stiftung, noviembre de 2014.

Lester, Simon e Inu Barbee, "The Challenge of Cooperation: Regulatory Trade Barriers in the Transatlantic Trade and Investment Partnership", Journal of International Economic Law, vol. 16, núm. 4, diciembre de 2013, pp. 847-867.

Lynch, Diahanna y David Vogel, "The Regulation of ogms in Europe and the United States: A Case Study of Contemporary European Regulatory Politics", Council on Foreign Relations, abril de 2001, http:// www.cfr.org/agricultural-policy/regulation-gmos-europe-united-states-case-study-contemporary-european-regulatory-politics/p8688

Mildner, Stormy y Oliver Ziegler, “A Long and Thorny Road: Regulatory Cooperation under the Framework for Advancing Transatlantic Economic Integration”, Intereconomics, núm. 44, enero-febrero de 2009, pp. 49-58.

Misión de la Unión Europea en los Estados Unidos, “Transatlantic Trade and Investment Partnership (TTIP): Creating Jobs, Boosting Exports, and Investing in the Economy of Tomorrow", hoja de datos, agosto 
de 2013, http://www.euintheus.org/wp-content/uploads/2013/07/ TTIP_Publicatiopn_85x11in_High_res.pdf

OECD, The Transatlantic Trade and Investment Partnership: Why Does It Matter?, febrero de 2013, http:/ / www.oecd.org/trade/TTIP.pdf

Oficina de Análisis Económico de los Estados Unidos, "U.S. Direct Investment: Balance of Payments and Direct Investment Position Data”, junio de 2015, http://www.bea.gov/international/dilusdbal.htm , "U.S. Trade in Goods and Services by Selected Countries and Areas, 1999 - present", diciembre de 2015, http://www.bea.gov/international/index.htm\#trade

Oficina de Censos de los Estados Unidos, "Foreign Trade: Trade with European Union”, septiembre 2015, disponible en http://www.census. gov/foreign-trade/balance/c0003.html

Oficina del Presidente de los Estados Unidos, The Economic Benefits of U.S. Trade, mayo de 2015, https://www.whitehouse.gov/sites/default/files/docs/cea_trade_report_final_non-embargoed_v2.pdf

Oficina del Representante Comercial de los Estados Unidos, "Anuncios sobre las Rondas de Negociación del TTIP”, https://ustr.gov/tradeagreements / free-trade-agreements / transatlantic-trade-and-investment-partnership/readouts

, "Declaraciones de Apertura de los Jefes Negociadores del TTIP en la Séptima Ronda de Negociaciones", octubre de 2014, https:// ustr.gov/about-us / policy-offices/press-office/speeches/2014/October/Opening-Remarks-by-US-and-EU-Chief-Negotiators-for-TTIPRound-Seven-Press-Conference

2012 U.S. Model Bilateral Investment Treaty, 2012, https://ustr. gov/sites/default/files/BIT 20text 20for 20ACIEP 20Meeting.pdf

—, 2014 Report on Sanitary and Phytosanitary Measures, marzo de 2014.

Oficina Europea de Estadística (Eurostat), "Extra-EU Trade by Partner", noviembre de 2015, http://appsso.eurostat.ec.europa.eu/nui/submitViewTableAction.do

Olivier, Christian, "Public Backlash Threatens EU Trade Deal with the US”, Financial Times, 13 de enero de 2015, http:/ /www.ft.com/intl/ cms/s/0/8c17a17e-9b33-11e4-882d-00144feabdc0.html\#axzz3cWM Tui6X 
омс, Base de Datos Estadísticos. Perfiles Comerciales, septiembre de 2014, http://stat.wto.org/CountryProfile/WSDBCountryPFReporter.aspx? Language $=\mathrm{S}$

_ , "Tariff Download Facility", 2015, http://tariffdata.wto.org/ReportersAndProducts.aspx

Parlamento Europeo, Dirección General para Políticas Internas, тTIP: Challenges and Opportunities for the Internal Market and Consumer Protection in the Area of Motor Vehicles, julio de 2015.

Paulsen, Lauge, Jonathan Bonnitcha y Jason Yackee, Transatlantic Investment Treaty Protection, Center for European Policy Studies/Johns Hopkins University, Reporte 102, marzo de 2015.

Quick, Reinhard, "Why TTIP Should Have an Investment Chapter Including ISDs", Journal of World Trade, vol. 49, núm. 2, 2015, pp. 199-209.

Sberro Picard, Stephan Joseph, "La negociación del TTIP: del interregionalismo a la gobernanza global", CIDOB d'Afers Internacionals, núm. 110 , septiembre de 2015 , pp. $67-86$.

Skovgaard Poulsen, Lauge N., Jonathan Bonnitcha y Jason Webb Yackee, "Costs and Benefits of an EU-USA Investment Protection Treaty", Londres, London School of Economics, abril de 2013.

Statement of the European Union and the United States on Shared Principles for International Investment, abril de 2012, http://trade.ec.europa.eu/doclib/docs/2012/april/tradoc_149331.pdf

UE, "Capítulo 2: Inversiones", en TTIP: Trade in Services, Investment and ECommerce, 12 de noviembre de 2015, http://trade.ec.europa.eu/doclib/docs/2015/november/tradoc_153955.pdf

Weaver, Mark, "The Proposed Transatlantic Trade and Investment Partnership (TTIP): ISDS Provisions, Reconciliation, and Future Trade Implications", Emory International Law Review 29, 2014, pp. 225-275. 